Archived version from NCDOCKS Institutional Repository http://libres.uncg.edu/ir/asu/

\title{
Appalachlyan
}

B O O N , N O R T H C A R O L I N A

\section{Responses To Hyperthermia. Optimizing Heat Dissipation By Convection And Evaporation: Neural Control Of Skin Blood Flow And Sweating In Humans}

\author{
By: Caroline J. Smith and John M. Johnson
}

\begin{abstract}
Under normothermic, resting conditions, humans dissipate heat from the body at a rate approximately equal to heat production. Small discrepancies between heat production and heat elimination would, over time, lead to sig- nificant changes in heat storage and body temperature. When heat production or environmental temperature is high the challenge of maintaining heat balance is much greater. This matching of heat elimination with heat pro- duction is a function of the skin circulation facilitating heat transport to the body surface and sweating, enabling evaporative heat loss. These processes are manifestations of the autonomic control of cutaneous vasomotor and sudomotor functions and form the basis of this review. We focus on these systems in the responses to hyperthermia. In particular, the cutaneous vascular responses to heat stress and the current understanding of the neurovascular mechanisms involved. The available research regarding cutaneous active vasodilation and vasoconstriction is highlighted, with emphasis on active vasodilation as a major responder to heat stress. Involvement of the vasoconstrictor and active vasodilator controls of the skin circulation in the context of heat stress and nonthermoregulatory re- flexes (blood pressure, exercise) are also considered. Autonomic involvement in the cutaneous vascular re- sponses to direct heating and cooling of the skin are also discussed. We examine the autonomic control of sweating, including cholinergic and noncholinergic mechanisms, the local control of sweating, thermoregulatory and nonthermoregulatory reflex control and the possible relationship between sudomotor and cutaneous vaso- dilator function. Finally, we comment on the clinical relevance of these control schemes in conditions of auto- nomic dysfunction.
\end{abstract}

Smith, C. \& Johnson, J. (2016). Responses To Hyperthermia. Optimizing Heat Dissipation By Convection And Evaporation: Neural Control Of Skin Blood Flow And Sweating In Humans. Autonomic Neuroscience: Basic and Clinical 196 (2016) 25-36. http://dx.doi.org/10.1016/j.autneu.2016.01.002. Publisher version of record available at: https://www.autonomicneuroscience.com/article/S1566-0702(16)30002-9/pdf 
Review

\title{
Responses to hyperthermia. Optimizing heat dissipation by convection and evaporation: Neural control of skin blood flow and sweating in humans
}

\author{
CarolineJ.Smith ${ }^{\mathrm{a},}$, , John M. Johnson ${ }^{\mathrm{b}}$ \\ ${ }^{a}$ Department of Health and Exercise Science, Appalachian State University, Boone, NC 28608-2071, United States \\ ${ }^{\mathrm{b}}$ Department of Physiology, University of Texas Health Science Center, San Antonio, TX 78229-3901, United States
}

\begin{abstract}
a b s t r a c t
Under normothermic, resting conditions, humans dissipate heat from the body at a rate approximately equal to heat production. Small discrepancies between heat production and heat elimination would, over time, lead to significant changes in heat storage and body temperature. When heat production or environmental temperature is high the challenge of maintaining heat balance is much greater. This matching of heat elimination with heat production is a function of the skin circulation facilitating heat transport to the body surface and sweating, enabling evaporative heat loss.

These processes are manifestations of the autonomic control of cutaneous vasomotor and sudomotor functions and form the basis of this review. We focus on these systems in the responses to hyperthermia. In particular, the cutaneous vascular responses to heat stress and the current understanding of the neurovascular mechanisms involved. The available research regarding cutaneous active vasodilation and vasoconstriction is highlighted, with emphasis on active vasodilation as a major responder to heat stress. Involvement of the vasoconstrictor and active vasodilator controls of the skin circulation in the context of heat stress and nonthermoregulatory reflexes (blood pressure, exercise) are also considered. Autonomic involvement in the cutaneous vascular responses to direct heating and cooling of the skin are also discussed. We examine the autonomic control of sweating, including cholinergic and noncholinergic mechanisms, the local control of sweating, thermoregulatory and nonthermoregulatory reflex control and the possible relationship between sudomotor and cutaneous vasodilator function. Finally, we comment on the clinical relevance of these control schemes in conditions of autonomic dysfunction.
\end{abstract}

Contents

1. Introduction.

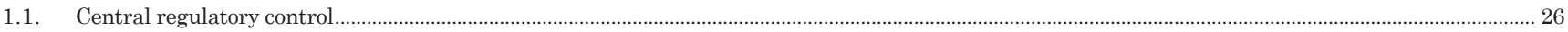

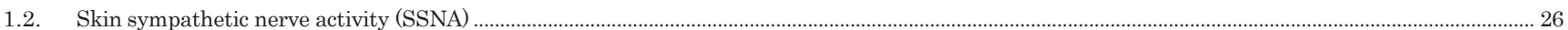

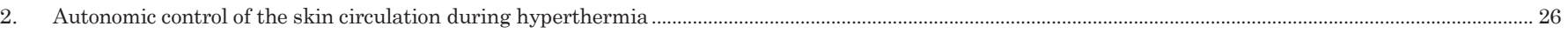

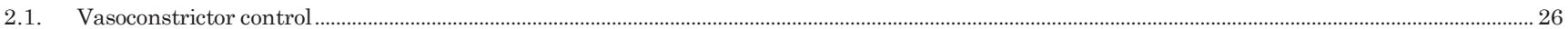

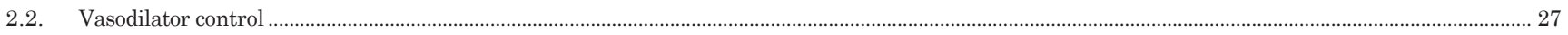

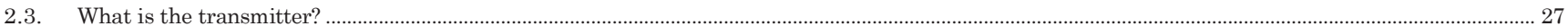

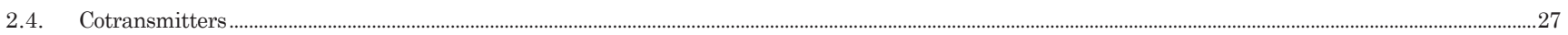

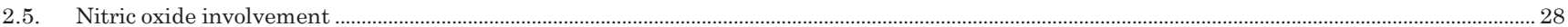

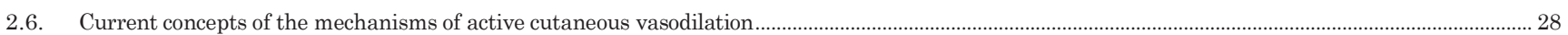

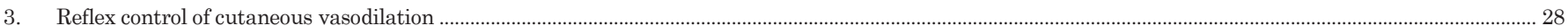

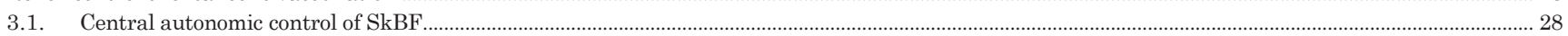

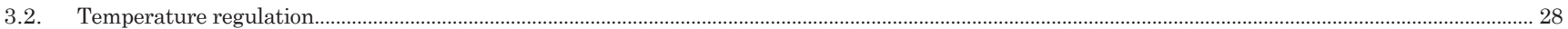

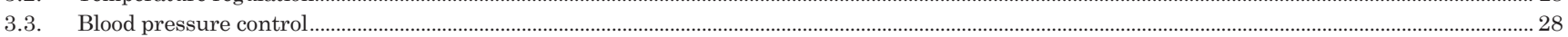

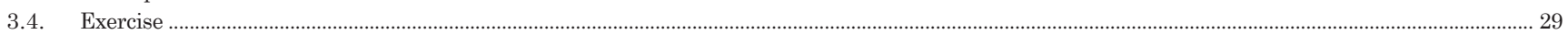

\footnotetext{
* Corresponding author at: 111 Rivers Street, Holmes Convocation Center 052, Department of Health and Exercise Science, Appalachian State University, Boone, NC 28608-2071, United
} States. 


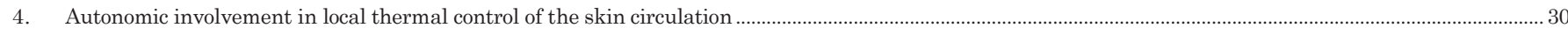

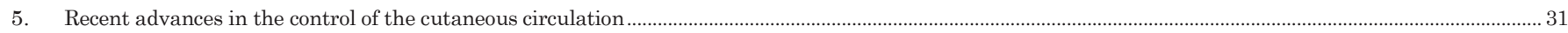

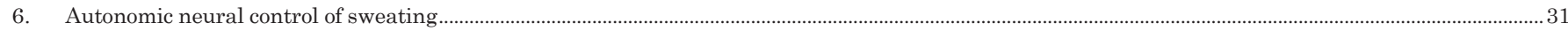

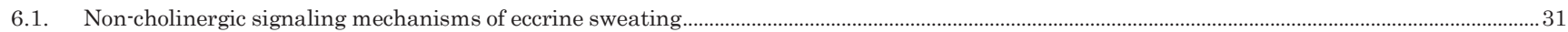

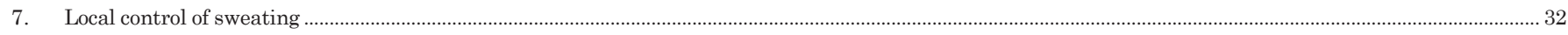

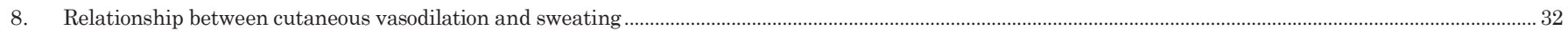

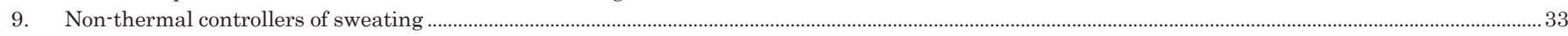

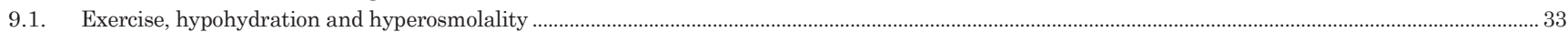

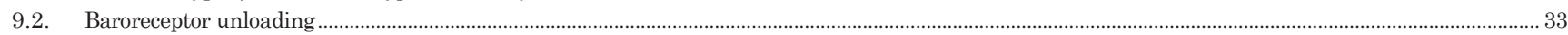

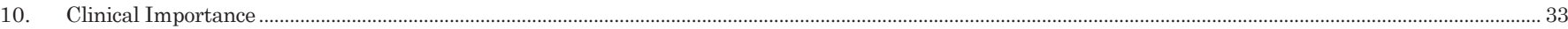

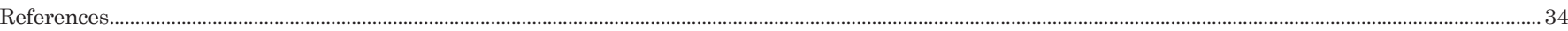

\section{Introduction}

Under normothermic conditions, subtle changes in body temperature are met by equally subtle vasomotor adjustments in the skin (Savage and Brengelmann, 1996; Charkoudian and Johnson, 2000), constituting the major means of homeothermy. During hyperthermia, elevated core (Tcore) and skin temperature (Tsk) elicit cutaneous vasodilation and sweating responses via the autonomic nervous system, and may be modulated by non-thermal factors. Conversely, under hypothermic conditions, cutaneous vasoconstriction is the first line of defense against heat loss, with metabolic heat production via shivering and non-shivering thermogenesis occurring in more severe conditions. The regulation of body temperature is largely accomplished by the autonomic nervous system and the skin as a target organ, with both the vasculature and eccrine sweat glands being of primary importance. In this review we provide an overview of the autonomic control of these responses to hyperthermia, focusing on skin sympathetic nerve activity, local signaling mechanisms at the skin, the influence of non-thermal factors, and a brief introduction of the clinical relevance of autonomic dysfunction in thermoregulation.

\subsection{Central regulatory control}

The thermoregulatory control center in humans is located in the preoptic anterior hypothalamus (POAH) (Moorhouse, 1911; Ott, 1887), which receives afferent input from both central and peripheral (skin) thermoreceptors (Benzinger, 1959). The importance of this area for thermoregulation has been demonstrated in animal models whereby local warming of the preoptic area elicits cutaneous vasodilation, panting, sweating, and behavioral modifications to increase heat loss (Gisolfi et al., 1988; Kanosue et al., 1994). The POAH receives, integrates and weights central and peripheral afferent signals. In warm environments a 9:1 ratio of core:shell (skin) afferent signals are integrated at the POAH, versus a ratio of approximately $4: 1$ in thermoneutral to cold conditions. Efferent sympathetic sudomotor signals originating from the POAH, travel via the ipsilateral brainstem via the tegmentum of the Pons and the medullary raphe nuclei before activating preganglionic neurons in the intermediolateral cell column of the spinal cord. After exiting from the ventral horn and passing via the white ramus communicans, these neurons synapse in close proximity to the spinal cord in the sympathetic ganglia. In the particular instance of heat stress, sudomotor and vasomotor control originate from these central centers. In this review we focus on the peripheral manifestations of those controls.

\subsection{Skin sympathetic nerve activity (SSNA)}

Sympathetic innervation of the skin is complex due to the presence of cutaneous vasodilator, vasoconstrictor, sudomotor, pilomotor and sensory fibers contained within cutaneous nerves. SSNA is measured via microneurography, in which 'bursts' of activity are recorded and the frequency and characteristics analyzed. The temporal variation of
SSNA differs from that of muscle, allowing identification of the different nerve branches. However, the complexity of SSNA poses significant challenges to identifying individual efferent signals, and therefore direct links with specific physiological responses. Attempts have been made to identify individual fiber activity, with evidence of sudomotor bursts being shorter in duration (Bini et al., 1980) and displaying a greater conduction velocity than vasoconstrictor bursts (Fagius and Wallin, 1980). Due to considerable variation and subsequent overlap between bursts, this is not a reliable means of differentiation among signals (Fagius and Wallin, 1980). Compared to normothermia, SSNA increases during hyperthermic conditions, reflecting increases in sudomotor and/or vasodilator activity. Notably, approximately $80 \%$ of SSNA bursts are synchronous with galvanic skin responses and pulsatile sweat expulsion during heat stress, indicating a potential dominance of the sudomotor signal under such conditions (Sugenoya et al., 1998). SSNA is typically measured in the leg, whilst skin blood flow (SkBF) and sweating response are frequently measured in the ventral forearm. The potential heterogeneity of SSNA to sudomotor and vasomotor function is currently unclear, both in a young, healthy population and with disease conditions involving autonomic dysfunction. Such heterogeneity may help explain the non-uniform age-related decrements in sweating and SkBF in different body regions despite similar cholinergic responsiveness (Smith et al., 2013a). SSNA declines with age in response to thermal stimuli (Grassi et al., 2003), contributing to thermoregulatory dysfunction and increased risk of heat-related illness and injury.

\section{Autonomic control of the skin circulation during hyperthermia}

Blood flow to the skin displays an incredible potential range, from nearly zero in extreme cold to 6-7 1/min during extreme heat stress (Johnson and Kellogg, 2010; Johnson et al., 2014; Rowell, 1974; Koroxeni. et al., 1961). Under normothermic conditions, total SkBF is approximately 250 - $300 \mathrm{ml} /$ minute. This entire range can be accomplished by autonomic adjustments involving two distinct nerve types, adrenergic vasoconstrictor and non-adrenergic vasodilator nerves.

\subsection{Vasoconstrictor control}

The vasoconstrictor control of the skin circulation is adrenergic and similar to that in other regional circulations. Norepinephrine and cotransmitters are released by the activity of adrenergic nerves, acting postsynaptically on appropriate receptors (for a detailed review of vasoconstriction refer to Johnson and Kellogg, 2010 and Johnson et al., 2014). The role the vasoconstrictor system plays in heat stress is one of withdrawal - "passive vasodilation" as opposed to the active vasodilation addressed below. This role is dependent on initial conditions. If there is extant vasoconstrictor nerve activity, heat stress will cause that activity to cease and a vasodilaton will ensue (Edholm et al., 1957). On the contrary, if there is no vasoconstrictor nerve activity to skin, no withdrawal is possible and there will be no contribution to the cutaneous vasodilation with heating (Roddie et al., 1957; Hodges et al., 2009). The circulation to glabrous skin as represented by palmar 
skin, is largely if not entirely under vasoconstrictor control (Gaskell, 1956; Johnson et al., 1995). Mild body warming causes a significant increase in hand blood flow. Blood flow to nonglabrous, hairy skin, as reflected by the forearm, has a much smaller dependence on vasoconstrictor nerve activity. Non-adrenergic vasodilation is prominent there (see below).

\subsection{Vasodilator control}

The skin circulation in humans has a non-adrenergic mechanism of vasodilation that causes an increase in $\mathrm{SkBF}$ with activation of a set of autonomic nerves; i.e., an increase in blood flow accompanying an increase in nerve activity (Edholm et al., 1957; Lewis and Pickering, 1931; Grant and Holling, 1938). This phenomenon is termed 'active vasodilation', in contrast to 'passive dilation' that accompanies a reduction in vasoconstrictor nerve activity. This is a means of control for which the mechanisms are not yet entirely clear but which can nevertheless exert a powerful vasodilator influence.

Several observations implicate the presence of active vasodilator control in the skin of humans. Lewis and Pickering (Lewis and Pickering, 1931) found, in patients with Raynaud's disease, that finger blood flow rose more with whole body heat stress than with anesthetization of the nerve supply to the finger. The latter mimics the effects of vasoconstrictor system withdrawal, implying that activation of a vasodilator nerve was required for the full vasodilator response to body heating. Ironically, later studies indicated the lack of an active vasodilator system in the human hand and fingers in health (Gaskell, 1956). The explanation for these apparently discrepant observations is not obvious. Perhaps the condition of Raynaud's disease makes the presence of a vasodilator system more evident through a background vasoconstrictor bias. An active vasodilator system exists on the back of the hand and fingers (Johnson et al., 1995) and may contribute to the observations by Lewis and Pickering (Lewis and Pickering, 1931). In keeping with this possibility, stimulation of the sympathetic chain can cause vasodilator responses in the sole and the ankle (Blumberg and Wallin, 1987; Lundberg et al., 1989).

Later observations firmly established the existence of a neurogenic vasodilator system in the forearm and other non-glabrous skin areas. Nerve block in the skin caused only a small increase in blood flow whereas general body heating caused a much greater vasodilator response (Grant and Holling, 1938). The implication is one of the reliance on a neurogenic vasodilator system in hairy skin. Anesthetization of cutaneous nerves after the vasodilator response to body heating is established causes a rapid and marked reduction in SkBF. Such anesthetization prior to body heat stress was seen to prevent the majority of the later vasodilator response when body heating was applied (Edholm et al., 1957). The effects of intracutaneous nerve block on the vasodilator response to body heating were quite similar to the effects of sympathectomy (Roddie, 1983), implying that there is a neurogenic vasodilator system and that it runs in the sympathetic chain, but is not adrenergic at the postganglionic level.

Pharmacological inhibition of vasoconstrictor nerve function provided further verification. Blair et al. (1960) found that intra-arterial infusion of bretylium (which blocks transmitter release from adrenergic nerve endings) (Haeusler et al., 1969) into the forearm eliminated vasoconstrictor responses but left intact the vasodilator responses to body heating. Similarly, Kellogg et al. (1989) applied bretylium iontophoretically to approximately $1 \mathrm{~cm}^{2}$ of skin and found the drug application completely blocked vasoconstriction to body cooling but had no measureable effect on the vasodilator response to body heating. These latter findings are specific to skin (Saumet et al., 1988); hence, contributions by blood flow to skeletal muscle are not of concern in the general conclusion of the presence of an active vasodilator system in human skin. Kenney et al. $(1991,1994)$ noted that neither systemic adrenergic alpha-1 nor alpha-2 receptor blockade affected the cutaneous vasodilator response to the hyperthermia of dynamic exercise, supporting non-adrenergic active vasodilation.

Collectively, the above observations are conclusive in the existence of an active vasodilator system in human non-glabrous skin that is sympathetic but is not adrenergic and that activation of this system is responsible for most of the heat stress induced increase in SkBF in those areas of skin. Its contribution to the vasodilation in glabrous skin is not clear, but if it exists must be small. The vasodilator system is not tonically active at normal body and environmental temperatures. Finally, in this treatment, we refer to an active vasodilator system because it is not clear that this is a straightforward effect of nerves ending on vascular smooth muscle. This is developed further below.

\subsection{What is the transmitter?}

The earliest tests were for acetylcholine via cholinergic muscarinic receptor blockade with atropine. The results were not a straightforward demonstration of elimination, or not, of the vasodilator response to heat stress. Several found that atropine, given intra-arterially or intradermally prior to heat stress, delayed but did not block the subsequent vasodilation (Roddie et al., 1957; Shastry et al., 2000; Kellogg et al., 1995; Kellogg et al., 2007). Atropine in the presence of established reflex vasodilation from heat stress had no discernable effect on blood flow. The above observations suggest a role for acetylcholine (via muscarinic receptors) in active vasodilation, but it is not a full explanation for the phenomenon.

\subsection{Cotransmitters}

Kellogg et al. (1995) brought some resolution to this issue when investigating the effects of postsynaptic (atropine) versus presynaptic (botulinum toxin perfusion) cholinergic nerve function blockade. As described above, atropine pretreatment delayed but did not eliminate reflex vasodilation. Sweating was blocked. Importantly, pretreatment with botulinum toxin eliminated the vasodilator and sweating responses to heat stress, providing strong evidence for cholinergic nerve involvement (Dolly and Aoki, 2006; Simpson, 1981). This difference between the effects of atropine and botulinum toxin on active vasodilation indicates an important role for a signaling molecule other than acetylcholine in vasodilation, i.e., a cholinergic cotransmitter.

A candidate proposed as the cholinergic cotransmitter is vasoactive intestinal polypeptide (VIP) (Bennett et al., 2003). VIP is localized in cholinergic nerve endings in the gut (Lundberg, 1996) and has vasodilator properties. Perfusion of a VIP receptor antagonist via microdialysis (i.e. fragment VIP10-28), caused a significant $42 \%$ reduction in reflex vasodilation during body heating. Pretreatment with atropine, with or without VIP10-28, had no measureable effect on the response. Because there are limitations in VIP10-28 receptor affinity, the remaining vasodilation may result from other cotransmitters or from incomplete receptor blockade. Use of an alternate inhibitor, a fragment of pituitary adenylate cyclase activating polypeptide (PACAP), PACAP6-38, had the same effects on active vasodilation as VIP10-28 (Kellogg et al., 2010; Kellogg et al., 2012). PACAP initiates vasodilation through some of the same receptors as VIP, and neither can currently be ruled out as candidates for active vasodilation.

One challenge to the conclusion that VIP is the cotransmitter comes from the observation that patients with cystic fibrosis have a paucity of VIP in cutaneous nerves (Heinzerian et al., 1985), but exhibit vasodilator responses to body heating similar to those see in healthy subjects (Savage et al., 1990), even in the presence of atropine (Kellogg et al., 2007). Whilst there is good evidence to support VIP as a cholinergic cotransmitter in cutaneous active vasodilation, the observations from cystic fibrosis patients complicate this conclusion.

Clearly, the active vasodilator system is more complex than what might be revealed by these straightforward approaches. 
There are several other neuroendocrine elements postulated to contribute to active vasodilation, but where they fit in the process is often less clear. Wong and Minson (2006) identified a possible role for neurokinin receptors in the active vasodilator process, with the agonist possibly being Substance P itself. Although generally associated with sensory nerves (Holzer, 1998; Milner etal., 2004), the role of SubstanceP in active neurogenic vasodilation is not known. Alternatively, a cotransmitter (or acetylcholine) might act in the interstitium to affect either the release of Substance P (or other neurokinin) or their receptors.

A potential role for sensory nerve function was suggested by Wong (2013), who pretreated areas of skin with topical anesthetic cream. This delayed the onset of the reflex vasodilator response to hyperthermia, but did not affect the ultimate levelof SkBF, echoing the effects of atropine (Roddie et al., 1957; Shastry et al., 2000). Assuming the local anesthetic had noeffect on efferent nerve function, it suggests that the role of sensory nerves is somehow integrated with cholinergic muscarinic function. How the sensory system is involved in active cutaneous vasodilation without perturbationsin Tsk creates a challenge to understand its role in active vasodilation. Such an involvement could be an explanation for the apparent role of vanilloid type channels (TRPV) in active vasodilation (Wong and Fieger, 2012). In this case, however, the blockade of TRPV-1 receptors with capsazapine reduced the peak vasodilator response to body heating, as opposed to the delay seen with topical anesthetic (see above).

Pharmacological blockade of histamine $\mathrm{H} 1$ receptors (Wong et al., 2004) led to the suggestion that histamine was at least part of the mechanism by which VIP caused cutaneous vasodilation (Wilkins et al., 2004). Studies utilizing H1 receptor inhibition combined with direct VIP perfusion during normothermia imply that if VIP is released from cholinergic nerves during body heating, any ensuing vasodilation may involve $\mathrm{H} 1$ receptors. Also, such release would stimulate the release of histamine from mast cells in the skin. These implications bear direct testing. Similarly, cyclooxygenase antagonism with locally applied ketorolac significantly reduced the reflex vasodilator response to body heating (McCord et al., 2006). As with histamine, it seems most likely that the prostaglandins involvement implied by these findings is stimulated by transmitter(s) released from vasodilator nerves rather than coming from the cholinergic nerves.

\subsection{Nitric oxide involvement}

Multiple studies have shown an important role for NO in cutaneous active vasodilation (Kellogg et al., 1998; Shastry et al., 1998). Blockade of NO synthase (NOS) enzymes reduces vasodilator responses to body heating by at least $30 \%$. In several studies, Kellogg et al. (2008a, b) used antagonists selective for endothelial NOS (eNOS) and neural NOS (nNOS), and consistently found the latter to significantly suppress active vasodilation during body heating in resting subjects whereas eNOS inhibition was more effective in reducing the vasodilator response to local skin heating. In contrast, McNamara et al. (2014) found eNOS inhibition to suppress the cutaneous vasodilator response to hyperthermia generated by dynamic exercise but nNOS inhibition had no measurable effect. The explanation for this apparent discrepancy is unknown. Notably, in none of these studies was there evidence of both NOS enzymes participating.

\subsection{Current concepts of the mechanisms of active cutaneous vasodilation}

The current evidence addressing cutaneous active vasodilation is summarized by Fig. 1, in which active vasodilation is initiated by central activation of sympathetic cholinergic nerves to skin. Acetylcholine acts early in heat stress, its actions succeeded by vasodilator actions of VIP, PACAPand/or other cotransmitters. These transmitters acton PAC1 and VPACreceptorsonendothelialcellsorvascularsmoothmuscletoproduce NO and prostaglandins (e.g., PGI2) and on mast cells to produce histamine. Lastly, sensorynervefunctionbecomesinvolvedthroughunknown mechanisms, but brings into play NK1 and TRPV1 receptors. This collection of actions brings about a profound vasodilation. Whether the initiating nerve is also a sudomotor nerve remains controversial and unresolved.

\section{Reflexcontrol of cutaneous vasodilation}

\subsection{Central autonomic control of SkBF}

The autonomic control of the skin circulation relies on the two arms of the sympathetic nervous system described above. Those nerves participate in the reflex components of temperature regulation and in reflexes not directly involved in temperature regulation.

\subsection{Temperature regulation}

The skin circulation is integral to the regulation of body temperature. Thermoregulatory reflexes are the major controllers of SkBF. Starting at normal brain and skin temperatures, there is typically a low level of vasoconstrictor nerve activity while the vasodilator system is quiet (Edholm et al., 1957; Hodges et al., 2009). The vasoconstrictor system is the way body temperature is maintained in its very narrow range in these conditions. Subtle changes in body or skin temperature are met by equally subtle changes in SkBF and heat elimination and, as a consequence, body temperature is held in a very narrow range. Cooling the skin over a large portion of the body surface initiates an increased vasoconstrictor nerve activity, release of norepinephrine and NPY and a reduction in SkBF. Increased Tsk is accompanied by abolition of any extant vasoconstrictor nerve activity. In the hand, such abolition will cause blood flow to rise markedly. In nonglabrous skin, the increase in blood flow at that time is small or nonexistent. As body heating continues and internal temperature rises, the sympathetic cholinergic active vasodilator system is engaged and blood flow in nonglabrous areas begins to increase and continues to rise with internal temperature until a true maximum is reached (Taylor et al., 1984). In resting conditions, especially, the onset and increase in active vasodilator activity are accompanied by increased sweating, allowing the elimination of the increased transport of heat to the skin. Also under conditions of rest, blood flow over the entire body can rise to very high values, perhaps exceeding $6 \mathrm{l} / \mathrm{min}$. Hence, the autonomic nerves to skin have the capacity to reduce $\mathrm{SkBF}$ to nearly zero or increase it to maximal values.

\subsection{Blood pressure control}

The potential for SkBF to increase subserves thermoregulation but is a threat to blood pressure regulation. This is especially the case with orthostasis in the heat, when total vascular conductance is elevated because of the vasodilated skin but cardiac output falls with the reduction in cardiac filling attending the upright posture. Several studies found significant cutaneous vasoconstriction when blood pressure was challenged by simulated or actual upright tilting in normothermic conditions and that this vasoconstrictor response persisted when the subject was made hyperthermic (Johnson et al., 2014; Beiser et al., 1970; Rowell et al., 1973; Crossley et al., 1966; Lind et al., 1968; Johnson, 1986; Kellogg et al., 1990; Crandall et al., 1996; Schlader et al., 2015) (for detail refer to Johnson et al., 2014). Selective blockade of sympathetic vasoconstrictor function (Kellogg et al., 1990; Crandall et al., 1996) or of active vasodilator function (Shibasaki et al., 2006), showed both vasoconstrictor and active vasodilator systems to participate in this vasoconstriction. In cool or thermally neutral conditions, the reflex reduction in $\mathrm{SkBF}$ with simulated orthostasis is via increased vasoconstrictor activity (Kellogg et al., 1990; Crandall et al., 1996). In hyperthermia, when the vasodilator system is activated, reductions in SkBF are brought about by both reduced vasodilator system activity and enhanced vasoconstrictor system activity (Kellogg et al., 1990; Crandall et al., 1996; Shibasaki et al., 2006). The implication from these observations is that the skin circulation is under control by 


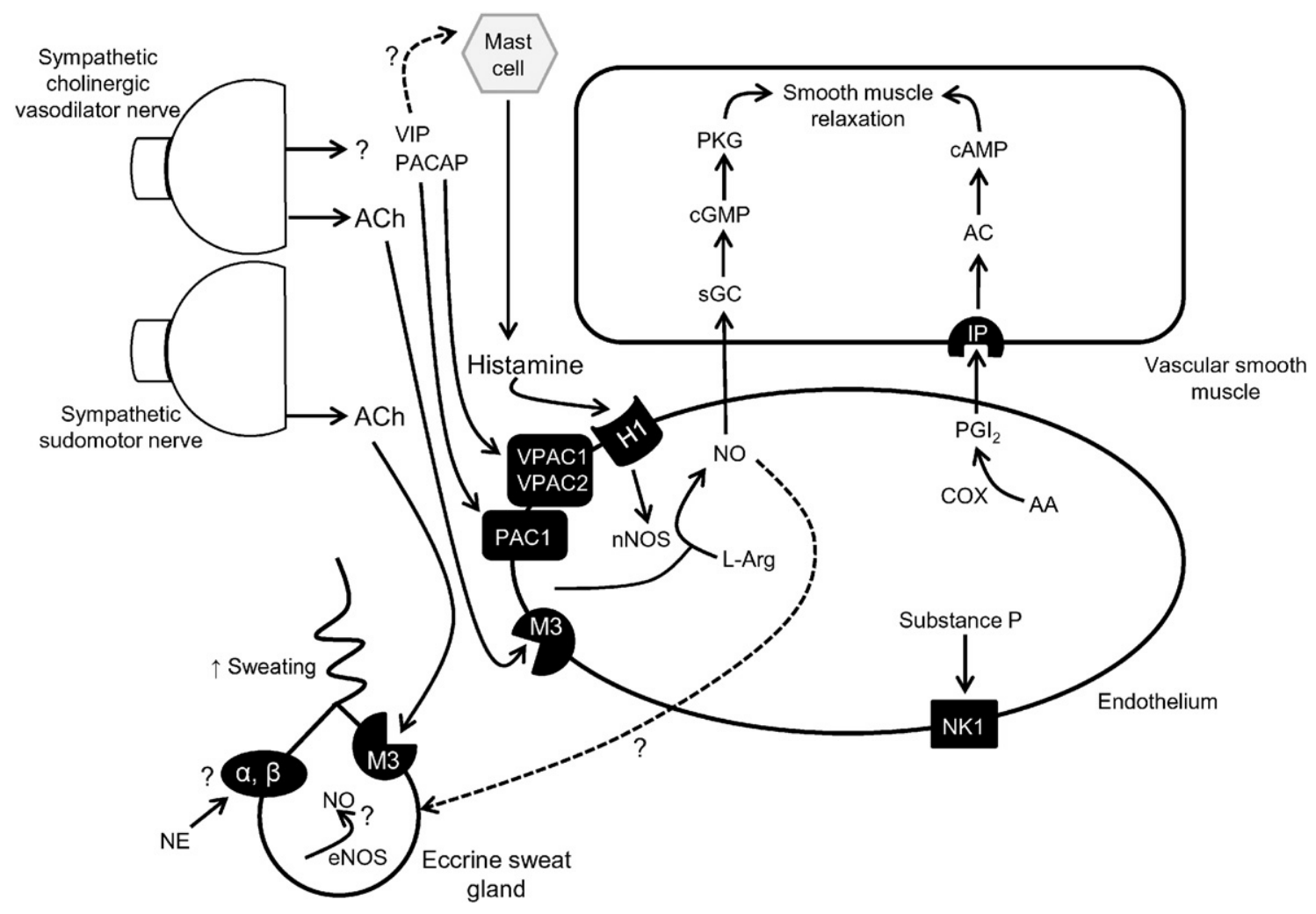

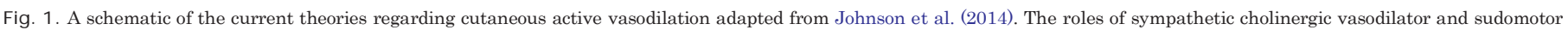

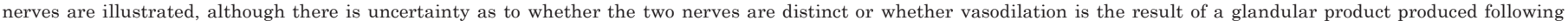

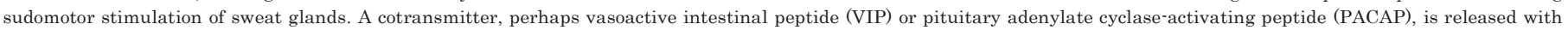

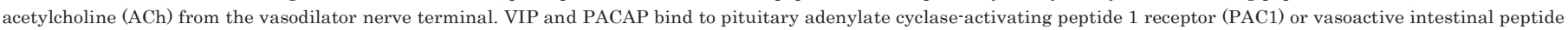

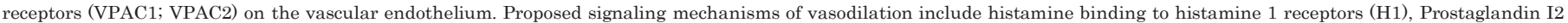

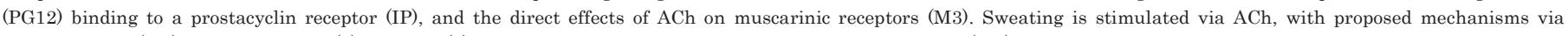

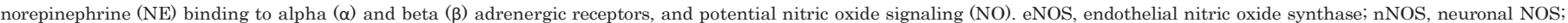

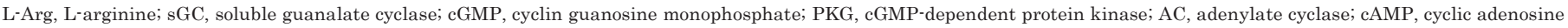
monophosphate; AA, arachidonic acid; COX, cyclooxygenase.

baroreceptors, although the distinction between roles for sinoaortic and cardiopulmonary receptors is not clear (Crandall et al., 1996).

Contrary to the above, direct recordings of SSNA typically do not reveal the pulse synchronous pattern seen in sympathetic nerve activity to skeletal muscle (Vissing et al., 1994; Wallin, 1990). Further, heroic measures to enhance vasoconstriction by simulated blood pressure challenges such as anesthetization of the glossopharyngeal and vagus nerves (carriers of blood pressure information from sinoaortic baroreceptors) were not associated with measureable changes in skin nerve activity (Fagius et al., 1985) nor was direct stimulation of the carotid sinus nerve (Wallin et al., 1975). Vissing et al. (1997) found changes in the elevation of the limbs could cause cutaneous vasoconstriction and argued that the response was a venoarterial reflex (Henriksen, 1977; Crandall et al., 2002) rather than a classic baroreflex. At this stage, there is no clear explanation for these discrepancies. It may be that the vasomotor contingent of skin nerve activity is small relative to the sensory and sudomotor components and does not contribute enough to mixed nerve recordings to reveal baroreflex modulation. It also may be that the regions of skin represented in the skin sympathetic nerve recordings (largely distal extremities) differ in baroreflex involvement from those from which blood flow is measured (usually forearm). It is hard to argue with the pale, cool skin of impending shock to dismiss a response in the skin circulation to blood pressure challenges.

\subsection{Exercise}

The distribution of the cardiac output during periods of dynamic exercise favors the active areas of skeletal muscle and the heart (Rowell,
1974). In the heat, that distribution is challenged and there is a compromise between meeting the needs of muscle during exercise and meeting the needs of temperature regulation (Rowell, 1974; Johnson, 1986; Kenney and Johnson, 1992). In hot conditions, humans can voluntarily exercise at levels sufficient to raise internal temperature to well over $40^{\circ} \mathrm{C}$, suggesting compromised temperature regulation. This suggests that exercise exerts a constraint over the skin circulation. When exercise begins, there is a cutaneous vasoconstriction (Zelis et al., 1969; Johnson and Park, 1982) accomplished by increased vasoconstrictor nerve activity both in normal thermal conditions and in heat stress (Kellogg et al., 1991a; Kellogg et al., 1991b). As exercise continues, internal temperature and SkBF rise, but the beginning of the increase in $\mathrm{SkBF}$ is delayed to a higher internal temperature than it would at rest (Johnson and Park, 1981; Taylor et al., 1988). This delay is through a central inhibition of the onset of active vasodilation (Kellogg et al., 1991b). Third, dynamic exercise in warm conditions has an upper limit to the increase in SkBF (Brengelmann et al., 1977). SkBF rises to an apparent upper limit while internal temperature continues to rise by another $1{ }^{\circ} \mathrm{C}$ or more. The level of SkBF is well below maximal or levels that would be expected under conditions of heat stress at rest. This upper limit is due to limiting active vasodilator activity while vasoconstrictor activity is being slowly withdrawn during the 'plateau' phase (Kellogg et al., 1993). In isometric exercise there is not the increase in heat production seen in dynamic exercise and the duration is necessarily short. The initiation of isometric exercise is not met with measureable changes in $\mathrm{SkBF}$ in nonglabrous skin, but is attended by a sharp vasoconstriction in skin of the palms and soles (Taylor et al., 1989; Saad et al., 2001). In this case, the response in glabrous skin is consistent with recordings of 
increased skin nerve activity during isometric exercise (Saito et al., 1990; Vissing and Hjortso, 1996).

\section{Autonomic involvement in local thermal control of the skin circulation}

Direct cooling or warming of the skin causes a vasoconstriction or vasodilation, respectively, via multiple mechanisms (Johnson and Kellogg, 2010; Johnson et al., 2014). NOS enzymes, principally eNOS (Kellogg et al., 1999; Kellogg et al., 2009; Bruning et al., 2012), play an important role in both local cooling and warming, being suppressed as part of the response to local cooling and activated with local skin heating (Kellogg et al., 1999; Hodges et al., 2006; Hodges et al., 2008). Hodges et al. (2006) found that local cooling suppressed the NOS enzyme and suppressed NO function downstream from NOS. Stimulation of warm sensitive nociceptors contributes to the vasodilator response to local skin warming, in part through stimulation of eNOS (Magerl and Treede, 1996; Minson et al., 2001; Stephens et al., 2001).

The classic response to local skin warming is described as an early transient peak, dependent on the rate of heating and due to an axon reflex, followed by a more slowly developing vasodilation (Hodges et al., 2009; Hodges et al., 2008; Magerl and Treede, 1996; Minson et al., 2001). As the time of local warming increases beyond 50 min or so, a phenomenon called a 'die away' is revealed, in which blood flow slowly falls despite continued heating (Hodges et al., 2008; Barcroft and Edholm, 1943). A sympathetic component of the skin vasomotor response to local warming was suggested by Charkoudian et al. (2002), who noted a loss of the initial transient peak in sympathectomized areas of skin. Houghton et al. (2006) found that blockade of transmitter release from adrenergic nerve terminals with locally applied bretylium eliminated that transient early response. Locally applied norepinephrine sensitized the area such that the axon reflex appeared at lower temperatures. A series of studies by Hodges and colleagues found, similarly, that post-synaptic blockade of adrenergic alpha and beta receptors and/or receptors for NPY delayed or eliminated the early axon reflex vasodilation (Hodges et al., 2009; Hodges et al., 2008; Hodges and Sparks, 2013; Hodges and Sparks, 2014). These actions likely act through eNOS and appear to vary with age and aerobic training (Tew et al., 2011a; Tew et al., 2011b). For example, in older sedentary subjects there is no apparent role for norepinephrine or NPY, whereas both are important in the response in young trained individuals, a difference suggested to be due to variation in sensory function between groups.

As warming progresses, the initial axon reflex is succeeded by a more sustained vasodilation, which is summarized in Fig. 2. There is substantial evidence that sympathetic function is important in that response. Either bretylium or yohimbine/propranolol or NPY antagonism pretreatment leads to a smaller vasodilator response in SkBF to local heating in that phase (Hodges et al., 2009; Hodges et al., 2008; Carter and Hodges, 2011). This observation is consistent with a requirement for those transmitters in the full expression of the cutaneous vascular response to skin warming. However, if adrenergic or NPY antagonism is delayed until after the vasodilation to local warming is established, there is no measureable effect (Hodges and Sparks, 2014). This finding is difficult to explain in the face of the effects of blockade prior to local warming, but indicates that, once established, the locally-mediated vasodilator process no longer requires adrenergic or NPY stimulation. This curious phenomenon deserves further study.

The third phase of the vasomotor responses to local skin warming is a slow decline in blood flow with prolonged periods of direct local heating (Barcroft and Edholm, 1943). This 'die away' phenomenon is dependent on intact sympathetic nerve function, as it is eliminated by blocking transmitter release from adrenergic terminals (Hodges et al., 2009). Hence, all three phases of the cutaneous vasomotor response to local skin warming; the initial axon reflex, the plateau and the die

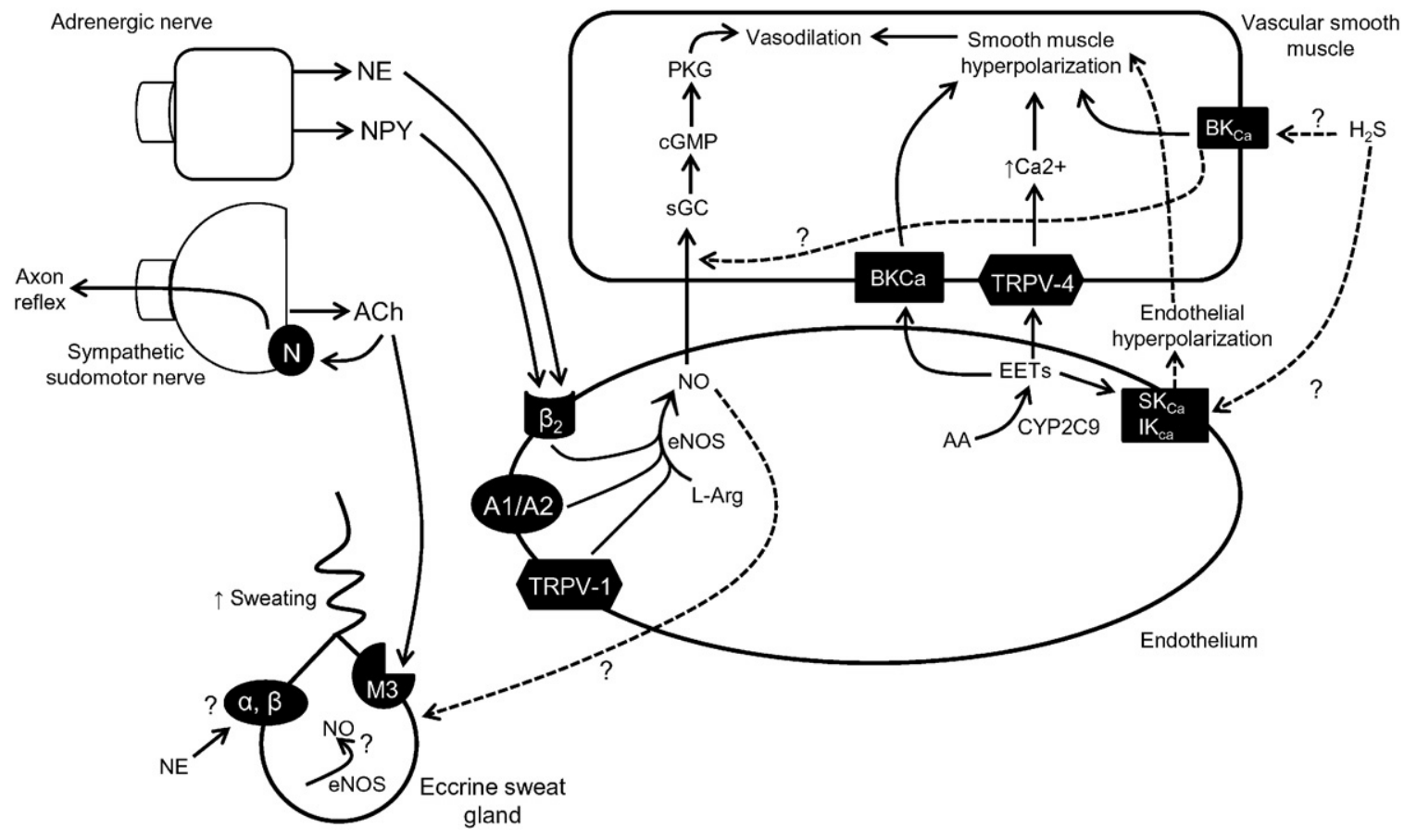

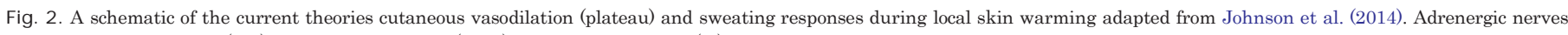

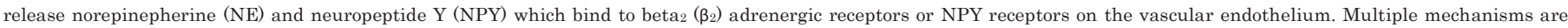

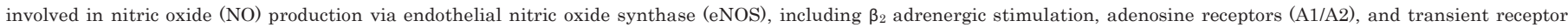

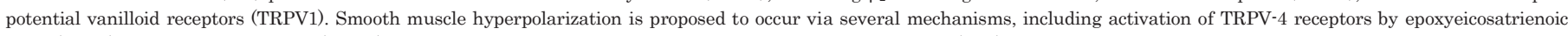

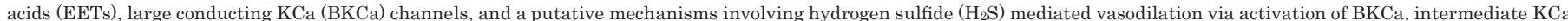

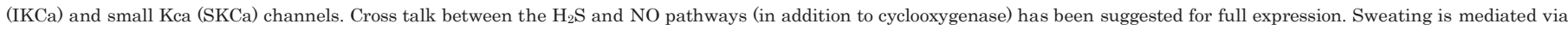

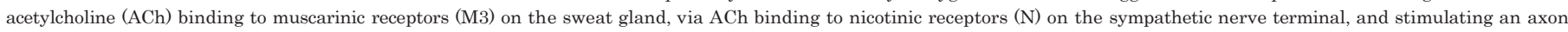

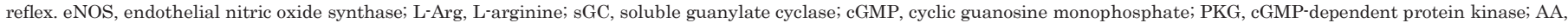
arachidonic acid. 
away phenomenon, rely on intact sympathetic function for their full expression. Where tested, both the primary transmitter norepinephrine and the cotransmitter NPY are shown to be involved in this role of sympathetic adrenergic function in locally stimulated vasodilation. Further, the action of sympathetic mediators in the axon reflex and in the plateau phase is one of NO-dependent vasodilation, an action opposite their role in regulatory reflexes such as whole body cooling or orthostasis.

\section{Recent advances in the control of the cutaneous circulation}

In addition to $\mathrm{NO}$ and sympathetic neurotransmission, other factors have come to light recently that may play a role in the cutaneous vascular responses to hyperthermia (Fig. 2). These other signaling pathways have received attention due to the prevalence of endothelial dysfunction in many clinical conditions. Also, the onset of microvascular dysfunction occurs in advance of dysfunction in conduit vessels (Abularrage et al., 2005; Joannides et al., 2006). The least well characterized of these factors are endothelium-derived hyperpolarizing factors (EDHFs), with considerable speculation as to their identity. EDHFs cause hyperpolarization of the vascular smooth muscle via heat sensitive TRPV4 channels and subsequent activation of calciumactivated potassium ( $\mathrm{KCa}$ ) channels on vascular endothelium and smooth muscle (Earley et al., 2005). Local KCa channel blockade in combination with NO inhibition with L-NAME nearly abolishes the cutaneous vasodilator response to local heating, with EDHFs being responsible for a large portion of the initial peak and $\sim 40-50 \%$ of the plateau phase (Brunt and Minson, 2012). Blockade of cytochrome P450, which converts arachidonic acid to epoxyeicosatrienoic acids (EETs), indicates that $~ 50 \%$ of EDHF-dependent vasodilation results from EETs (Brunt and Minson, 2012). The remaining 50\% of EDHFmediated vasodilation likely results from other signaling molecules acting via $\mathrm{KCa}$ channels, with hydrogen sulfide $\left(\mathrm{H}_{2} \mathrm{~S}\right)$ emerging as a strong candidate. $\mathrm{H}_{2} \mathrm{~S}$ is a potent gasotransmitter that appears likely to have an important role as a regulator of vascular homeostasis. In vivo and in vitro animal studies have demonstrated $\mathrm{H}_{2} \mathrm{~S}$-mediated vasodilation via multiple mechanisms including, activation of ATP-sensitive $\left(\mathrm{K}_{\mathrm{ATP}}\right)$ or voltage-gated (Kv7; KCNQ) potassium channels in vascular smooth muscle, and via activation of eNOS, thus demonstrating an NOcomponent for full expression. Unlike mechanisms of NO-dependent vasodilation, $\mathrm{H}_{2} \mathrm{~S}$ acts independently of cGMP and directly hyperpolarizes vascular smooth muscle to elicit vasodilation. Kutz et al. (2015) recently demonstrated a vasodilator role of $\mathrm{H}_{2} \mathrm{~S}$ in the human cutaneous circulation when administered via intradermal microdialysis. The enzymes responsible for endogenous $\mathrm{H}_{2} \mathrm{~S}$ production were identified in skin, adding weight to a functional role in cutaneous vasodilation. $\mathrm{H}_{2} \mathrm{~S}$ appears to have an important vasoprotective role, inhibiting vascular smooth muscle cell proliferation (Go et al., 2012; Li et al., 1833), platelet aggregation (Zhong et al., 2014), and inflammatory responses (Yu et al., 2014). Limited data are available regarding the functional role of $\mathrm{H}_{2} \mathrm{~S}$ in the control of the cutaneous circulation in hyperthermia.

\section{Autonomic neural control of sweating}

Evaporation of sweat from the skin surface is the greatest avenue of heat loss in hyperthermia. Under such conditions both Tcore (deep body temperature) and Tsk become elevated, causing increases in sweating and SkBF. It is widely accepted that brain temperature is the primary controller of sweating (Kuno, 1956), with a secondary influence of Tsk. Further modulation of sweating also results from changes in local Tsk and non-thermal factors, including dehydration, baroreflex unloading and exercise.

Sudomotor impulses originating from the POAH are transmitted to eccrine sweat glands via sympathetic postganglionic non-myelinated C-fibers (Uno, 1977). Acetylcholine is released from periglandular nerve endings, transverses the neuroglandular junction, and stimulates sweating via M3 muscarinic receptors on eccrine sweat glands (Fig. 1).
Even in cooler environments with an absence of visible sweating, subthreshold sympathetic sudomotor impulses at the neuroglandular junction stimulate clear cells of the secretory coil to release a plasma-like precursor ultrafiltrate into the lumen (Ogawa and Bullard, 1972). The ultrafiltrate is modified along the length of the sweat duct before expulsion as a hypotonic solution onto the skin surface. The appearance and quantity of visible sweat is dependent upon the rates of production and reabsorption of the precursor ultrafiltrate. Sweating rate is largely influenced by the concentration of acetylcholine released from the cholinergic nerve terminal, which is rapidly hydrolysed into choline and acetate by acetylcholinesterase (Longmore et al., 1986). As such, acetylcholinesterase is capable of influencing sweating at lower rates, but its effectiveness in reducing local sweating is limited at higher sweating rates (Shibasaki and Crandall, 2001). The amount of sweat that reaches the skin surface is dependent upon sympathetic innervation and local conditions at or around the gland (Ogawa and Bullard, 1972; Ogawa and Sugenoya, 1993).

Considerable regional variation in sweating rates exists over the body (Kuno, 1956; Cotter et al., 1995; Taylor et al., 2006; Machado-Moreira et al., 2008a; Machado-Moreira et al., 2008b; Machado-Moreira et al., 2008c; Smith and Havenith, 2011; Smith and Havenith, 2012; Havenith et al., 2008; Hertzman, 1957), being greatest on the forehead, central (medial) and lower back, in addition to the skin region between the breasts in females. Lowest thermoregulatory sweating is towards the extremities, specifically on the fingers and palms (Machado-Moreira et al., 2008a; Machado-Moreira et al., 2008c; Smith and Havenith, 2011; Smith and Havenith, 2012). Despite large variation among individuals in absolute sweat rates, this pattern of high- versus low regional distribution is observed, probably due to differences in output per gland (Kuno, 1956; Smith and Havenith, 2011; Smith and Havenith, 2012; Inoue and Shibasaki, 1996). Potential heterogeneity of SSNA to sweat glands, or region-dependent differences in SSNA may contribute. Putative heterogeneity in SSNA during hyperthermia may explain non-uniform regional sweating and SkBF observed over the body, but no definite conclusions can be drawn from current data.

\subsection{Non-cholinergic signaling mechanisms of eccrine sweating}

Whilst acetylcholine is accepted as the main neurotransmitter involved in thermoregulatory sweating, adrenergic receptors have been identified on eccrine sweat glands, suggesting a role in thermoregulatory sweating. Noradrenergic neurons have been identified close to eccrine sweat glands (Uno, 1977; Donadio et al., 2006), although both the density in close proximity to eccrine sweat glands and the number of adrenergic receptors on the glands themselves are far fewer than cholinergic neurons and cholinergic (M3) receptors, respectively. Exogenous administration of adrenergic agonists can elicit sweating, albeit only minimally (Allen and Roddie, 1972; Wolf and Maibach, 1974; Sato and Sato, 1981), although overall the results have varied. Either alpha $(\alpha)$ or beta $(\beta)$-adrenergic stimulation elicits a sweating response during in vitro preparations of sweat glands from rhesus monkeys, with the latter having a much greater effect. $\alpha$-adrenergic stimulation produces only a minimal response (in humans and animal studies), yet a cumulative effect may be present when both receptor types are stimulated (Sato and Sato, 1981; Aoki et al., 1984). During in vitro investigation of isolated monkey palmar eccrine sweat glands, Sato and Sato (1981) observed relative effects of 4:2:1 for cholinergic, $\beta$-adrenergic, and $\alpha$-adrenergic stimulation on sweating rate, respectively. In other studies of $\beta$-adrenergic blockade on sweating rate, using oral propranolol, also elicited mixed results, with sweating rates increasing (Wilcox et al., 1984; Freund et al., 1987), decreasing (Buono et al., 2010), or showing no change (Pescatello et al., 1990). This is likely due to the systemic effects of propranolol, including decreases in heart rate (Wilcox et al., 1984; Pescatello et al., 1987), blood pressure (Wilcox et al., 1984), cardiac output, both skeletal and SkBF, and reported decreases in Tsk (Freund et al., 1987; Mack etal., 1986) and increased Tcore during 
exercise (Pescatello et al., 1987; Mack et al., 1986). Mora-MoraRodriguez et al. (1996) measured sweating rates during exercise while administering intravenous infusions of saline, glucose, or epinephrine, and observed no significant difference in sweating rate among trials, despite significantly greater plasma catecholamine concentrations during the epinephrine infusion. During hyperthermia, sweating may be significantly attenuated or completely abolished via administration of the muscarinic antagonist atropine, supporting cholinergic dominance in mechanisms of human eccrine sweating (Machado-Moreira et al., 2012).

Whilst acetylcholine is the major neurotransmitter responsible for eccrine sweating, a number of other substances and mechanisms can stimulate or modify the response at the level of the gland. During hyperthermia, arterial plasma ATP is known to increase (Pearson et al., 2011; Kalsi and González-Alonso, 2012) and has been implicated in the control of eccrine sweating. Sympathetic cholinergic nerves co-release ATP with acetylcholine (Rabasseda et al., 1987), with increases in sweating demonstrated in vitro with administration of ATP. P2Y receptors have been identified in human sweat glands (Lindsay et al., 2002a; Lindsay et al., 2002b), however, in vivo responses and the mechanisms involved are less clear. Fujii et al. (2015) recently found no direct role of ATP in the sweating response, but modulation of cholinergic sweating during heat stress and exercise cannot be ruled out and further investigation may be warranted. Multiple putative signaling molecules involved in sweating have been identified within the periglandular sympathetic nerves, including, VIP, CGRP, galanin, NE, and ATP (Rabasseda et al., 1987; Tainio et al., 1987; Lindh and Hokfelt, 1990; Lundberg et al., 1980; Kennedy et al., 1994). When administered locally they elicit a sweating response (Schlereth et al., 2006), yet their functions in the regulation of sweating are controversial and are not fully understood. A number of these substances have also been implicated in cutaneous vasodilation, adding increasing speculation to a common signaling mechanism between the two thermoregulatory responses (see below).

\section{Local control of sweating}

Stimulation of sweating by local heating was first observed by Sato (1956) in the footpad of cats. Subsequent studies have extensively documented the effects of local heating on sweating in humans (Ogawa and Asayama, 1986; Ogawa, 1970; Gisolfi and Robinson, 1970; Nadel et al., 1971; Wurster and McCook, 1969). Specifically, local heating above $42^{\circ} \mathrm{C}$ can elicit a local sweating response via direct glandular activation, even in cool temperatures when whole body sweating is absent (Issekutz et al., 1950; Lloyd, 1961). Local heating of $20-40^{\circ} \mathrm{C}$ can intensify the local sweating rate, but whole body sweating must be present, indicating that adequate efferent sudomotor impulses must occur for modification at the glandular level under these conditions (Bullard et al., 1967; MacIntyre et al., 1968). Modulation occurs via increased acetylcholine release at the neuroglandular junction and increased sensitivity of the sweat gland to acetylcholine, enhancing the local sweat rate for a given thermal drive (Ogawa and Sugenoya, 1993; Ogawa and Asayama, 1986; Ogawa, 1970).

In addition to the direct effects of acetylcholine on M3 muscarinic receptors, a sudomotor axon reflex is also triggered (Fig. 2). Acetylcholine binds to axonal nicotinic receptors and evokes a neural impulse which is thought to travel antidromically from the axon terminal along the postganglionic sympathetic sudomotor fiber. Upon reaching a branch point, the impulse travels orthodromically to other eccrine sweat glands and stimulates sweating via an indirect axon-reflex (Illigens and Gibbons, 2009; Namer et al., 2004). Utilization of this mechanism has gained widespread clinical use (i.e. the quantitative sudomotor axon reflex test, QSART) to assess postganglionic sympathetic cholinergic sudomotor function in, for example, type 2 diabetes, and reflex sympathetic dystrophy. Sudomotor dysfunction is prevalent in many autonomic neuropathies and therefore holds significant clinical value as a non-invasive test of autonomic function.

\section{Relationship between cutaneous vasodilation and sweating}

Cutaneous vasodilation is important in thermoregulatory sweating not only in providing the heat required for evaporation of sweat, but by providing blood plasma as the necessary precursor fluid for sweat production. It might therefore be expected that both sweating and SkBF responses would show greatest values in similar body regions; however, this is not the case (Smith et al., 2013a; Smith et al., 2013b). Regional variation in sweating over the body surface in humans is well documented (Kuno, 1956; Cotter et al., 1995; Taylor et al., 2006; Machado-Moreira et al., 2008a; Machado-Moreira et al., 2008b; Machado-Moreira et al., 2008c; Smith and Havenith, 2011; Smith and Havenith, 2012; Havenith et al., 2008; Hertzman, 1957), yet far less regional variation in $\mathrm{SkBF}$ is observed in young, healthy individuals during passive hyperthermia or pharmacological stimulation (Smith et al., 2013b).

The suggestion of a mechanistic link between sudomotor function and active cutaneous vasodilation originated from Fox and Hilton (1958), who hypothesized that an enzyme released from the activated sweat gland would cleave bradykinin, a potent vasodilator, in the interstitial space, leading to active vasodilation. This was based on similar glandular effects on blood flow in salivary glands and the generally parallel patterns of sweating and blood flow during body heating. Sweating and active vasodilation are reported to occur at similar times during hyperthermia, suggesting shared sympathetic neural mechanisms. This was further supported by the absence of an active vasodilator response in individuals with anhidrotic ectodermal dysplasia, who have a congenital absence of sweat glands (Brengelmann et al., 1981). Furthermore, both cutaneous vasodilation and eccrine sweating are augmented upon co-release of VIP and acetylcholine (Yamashita et al., 1987), adding further weight to a mechanistic link.

Sympathetic sudomotor function and active vasodilation are both cholinergic as they are blocked by intradermal botulinum toxin (Kellogg et al., 1995) yet post-junctional blockade of muscarinic receptors with atropine blocks sweating but has only minor effects on cutaneous vasodilation. Blockade of bradykinin receptors was without effect on active vasodilation, eliminating that as a specific intermediate (Kellogg et al., 2002). There is debate whether nerves innervating the cutaneous vasculature and sweat glands constitute a single nerve or are in fact separate (see Fig 1). More recently, common signaling molecules for the two responses have been investigated, including calcitonin gene-related peptide (CGRP), substance P, VIP, and NO (Fujii et al., 2015; Stapleton et al., 2014; Journeay et al., 2004). The primary neurotransmitter responsible for active cutaneous vasodilation remains uncertain, maintaining speculation that sympathetic nerve cotransmission mediates vasodilation (Kellogg et al., 1995) and may also modulate the sweating response.

VIP is a candidate for the elusive cotransmitter and a focus of many studies. Evidence for VIP immunoreactive nerve fibers surrounding sweat glands was demonstrated on cat foot pads (Lundberg et al., 1980; Kummer et al., 1990) by Lundberg and colleagues as early as 1979 and later in human eccrine sweat glands (Kummer et al., 1990; Eedy et al., 1990). VIP is a potent vasodilator, and has also been shown to enhance sweating (Vaalasti et al., 1985). Binding sites for VIP have been identified on human eccrine sweat glands (high and low affinity) suggesting a regulatory role for VIP (Heinz-Erian et al., 1986). Currently, despite the coexistence of VIP and acetylcholine in cholinergic sympathetic nerve terminals and the presence of receptors on eccrine glands, the putative mechanistic involvement of VIP in a functional relationship between sweating and $\mathrm{SkBF}$ is yet undetermined.

The important role of NO in vascular signaling has received considerable attention in recent years, and its mechanisms of action have been extensively studied. Whilst a thermally-mediated vasodilator action of NO, and NOS enzymes has been established (Kellogg et al., 1998; 
Kellogg et al., 2009; Bruning et al., 2012; Minson et al., 2001; Kellogg, 2006; Smith et al., 2011), a putative NO-signaling mechanism for eccrine sweating has been suggested. Flow-mediated changes in $\mathrm{NO} \mathrm{re}^{-}$ lease may modulate sweating at a given thermal drive, in addition to the possible role of an NO-dependent pathway acting to modify sweat production within the sweat gland itself. However, evidence for such a signaling pathway is mixed. Several authors observed an attenuation of sweating rate following NOS-inhibition (Stapleton et al., 2014; Lee and Mack, 2006; Welch et al., 2009a), suggesting a possible role for NO in eccrine sweating (Welch et al., 2009b). Conversely, NOS inhibition showed negligible effects on sweating rate during whole body passive heating (Kellogg et al., 1998; Shastry et al., 1998). Overall limited data support an NO-dependent signaling pathway for eccrine sweating, yet, eNOS has been identified in clear cells which produce a sweat precursor fluid in eccrine sweat glands (Shimizu et al., 1997). NO may play a role in sweat gland activation via intracellular calcium influx during acetylcholine-mediated sweating, additionally activating NOS and subsequent production of NO. Currently, the presence of an NO-signaling mechanism in eccrine sweat glands, and a functional relationship between sweating and $\mathrm{SkBF}$ requires further investigation.

When considering common mechanisms in the control of SkBF and sweating responses, it is of value to investigate these responses in specific populations and pathologies. Non-uniform decrements in both responses have been observed with primary aging, whereby SkBF significantly declines in older individuals, initially towards the peripheral with little difference on the abdomen in comparison to younger individuals (Smith et al., 2013a). Conversely, whilst regional sweating rates are significantly lower in older versus younger individuals during whole body warming, the differences are far greater on the back and abdomen compared to the extremities (arm and thigh) in the older group. Decrements in sweating appear greater than those observed in cutaneous vasodilation, suggesting age-related differences in end organ responsiveness, or attenuation of other potential signaling mechanisms involved in the control of sweating ad SkBF (Smith et al., 2013a). Further work is required exploring the mechanistic and functional links between sweating and $\mathrm{SkBF}$, and the important clinical implications for disease groups whose thermoregulatory capacity is diminished.

\section{Non-thermal controllers of sweating}

Thermoregulatory responses are modified by several factors independent of Tcore, involving complex mechanisms of regulation resulting from involvement of many, often competing body systems. A brief introduction to these mechanisms is introduced below (refer to Cheuvront and Kenefick in this special edition for a more detailed review).

\subsection{Exercise, hypohydration and hyperosmolality}

During exercise, production of large amounts of heat as a byproduct of muscular contraction elicits rapid increases in Tcore and initiation of cutaneous vasodilation and sweating. Sweating occurs within seconds of the onset of both dynamic exercise and short duration isometric exercise when performed in a warm environment (Vanbeaumont and Bullard, 1963; Yanagimoto et al., 2003; van Beaumont and Bullard, 1966). Notably, these rapid sweating responses occur prior to any increase in Tcore or Tsk, indicating exercise itself independently modulates sweating. During intermittent dynamic exercise, sweating responses rapidly increase during the work periods independent of changes in Tcore, Tsk or muscle temperature. Similarly, during sinusoidal exercise, sweating has been shown to mirror the sinusoidal workload pattern and not alterations in Tcore and Tsk (Yamazaki et al., 1996; Yamazaki et al., 1994).

During periods of profuse sweating when fluid intake is insufficient to replace losses, hypohydration results. During progressive dehydration, plasma volume is reduced, leading to hypovolemia accompanied by hyperosmolality in instances of more severe hypohydration. Higher heart rate and Tcore responses are observed with increasing magnitudes of hypohydration, and significantly lower sweating rates for a given Tcore (Sawka et al., 1985). During exposure to heat stress a right shift in the Tcore-sweating threshold has been observed in normovolemic hyperosmotic conditions relative to normovolemic isoosmotic conditions, yet the slope of the Tcore-sweating relationship is unaffected (Montain et al., 1995; Fortney et al., 1984). Whilst isoosmotic hypovolemia attenuates sweating, plasma hyperosmolality is capable of reducing sweating independent of plasma volume. Overall, a linear increase in thermal strain is observed with progressive hypohydration (Sawka et al., 1985), potentially leading to heat-related illness, injury and possibly death if Tcore remains dangerously elevated.

\subsection{Baroreceptor unloading}

Studies of the effects of baroreceptor function on sweating responses have produced mixed results. Wilson et al. (2001) observed no effect of pharmacologically induced baroreceptor unloading and immediate reloading during passive heat stress, achieved via infusions of sodium nitroprusside and phenylephrine, respectively. Similarly, multiple studies involving a range of techniques designed to elicit baroreflex unloading, including passive heat stress coupled with lower body negative pressure, head up tilt, or infusion of pharmacological agents, have demonstrated no effect on sweating rates during passive heat stress. Kenny et al. (2010) observed no difference in sweating or cutaneous blood flow during upright seated versus $15^{\circ}$ head-down tilt during passive heating, confirming earlier results. Similarly, Schlader et al. (2015) observed an attenuated vasodilation with cardiopulmonary and arterial baroreceptor unloading, but no effect on sweating rate during passive heat stress. Notably, similar results have been observed during exercise, yet cardiopulmonary and/or baroreflex unloading consistently reduces sweating rate during post-exercise recovery (Journeay et al., 2004). Baroreflex reloading via lower body positive pressure (Journeay et al., 2004) or head down tilt (Journeay et al., 2007; McInnis et al., 2006) augments sweating and reduces return time to baseline Tcore versus control conditions, subsequently improving thermoregulatory recovery to exercise in warm conditions. It is important to consider the level of hyperthermia with extreme heat stress, and therefore a high thermal drive, superseding non-thermal modulation of sweating (Kondo et al., 2002).

\section{Clinical Importance}

Autonomic dysfunction is a feature of many clinical conditions, resulting in potentially severe or fatal symptoms. For a comprehensive review of the clinical relevance of thermoregulatory dysfunction in conditions associated with autonomic dysfunction, please refer to other reviews within this special addition. In such populations, for example type 2 diabetic neuropathy (Fagius and Wallin, 1980), the consequences of blunted sweating and SkBF responses significantly comprise thermoregulatory ability, resulting in increased susceptibility to heat-related illness, injury, and potentially death. Considering the wide fluctuations in $\mathrm{SkBF}$ over the entire body, ranging from $\sim 250 \mathrm{ml} / \mathrm{min}$ in normothermic conditions to 6-7 L/min during heat stress, coupled with the significant capacity for heat loss via evaporation of sweat, heat-related illness in clinical populations is not surprising. Sudomotor dysfunction is known to occur in many types of neuropathy and more specifically, is considered one of the earliest detectable alterations in distal small fiber neuropathy (Low et al., 2006). Utilizing various 'sweat tests' provides an important clinical tool for assessment of autonomic (dys)function, evaluating the success of specific treatment, and for monitoring disease progression (Illigens and Gibbons, 2009). Similarly, endothelial dysfunction occurs in the microcirculation (i.e. the skin) prior to dysfunction in conduit vessels, is present prior to the onset of overt cardiovascular disease symptoms, and therefore occurs in subclinical populations (Holowatz et al., 2008). When exposed to heat stress, older individuals (Minson et al., 1998) and many clinical populations experience considerable cardiovascular strain when attempting to 
dissipate heat via a compromised thermoregulatory system, with increased risk of a cardiovascular event. Greater consideration needs to be given to the risks of thermoregulatory dysfunction in clinical populations, exemplified by dangerous sauna use in type 2 diabetic peripheral neuropathy, and with the disproportionately high incidence of heatrelated illness and injury during heat waves in individuals over the age of 65 (Kenney et al., 2014).

\section{References}

Abularrage, C.J., Sidawy, A.N., Aidinian, G., Singh, N., Weiswasser, J.M., Arora, S., 2005. Evaluation of the microcirculation in vascular disease. J. Vasc. Surg. 42, 574-581.

Allen, J.A., Roddie, I.C., 1972. The role of circulating catecholamines in sweat production in man. J. Physiol. 227, 801-814

Aoki, T., Narita, T., Sato, H., Izumi, H., 1984. Failure to produce axon reflex sweating in the volar skin of Japanese monkey (Macaca Fuscata) and crab-eating monkey (Macaca Irus). Comparative Biochemistry and Physiology Part C: Comparative Pharmacology. 79, 325-329.

Barcroft, H., Edholm, O.G., 1943. The effect of temperature on blood flow and deep temperature in the human forearm. J. Physiol. Lond. 102, 5-20.

Beiser, G.D., Zelis, R., Epstein, S.E., Mason, D.T., Braunwald, E., 1970. The role of skin and muscle resistance vessels in reflexes mediated by the baroreceptor system. J. Clin. Invest. $49,225-231$.

Bennett, L.A.T., Johnson, J.M., Stephens, D.P., Saad, A.R., Kellogg, D.L., 2003. Evidence for a role for vasoactive intestinal peptide in active vasodilatation in the cutaneous vasculature of humans. J. Physiol. 552, 223-232.

Benzinger, T.H., 1959. On physcial heat regulation and the sense of temperature in man. Proc. Natl. Acad. Sci. U. S. A. 45, 645-659.

Bini, G., Hagbarth, K.E., Hynninen, P., Wallin, B.G., 1980. Thermoregulatory and rhythmgenerating mechanisms governing the sudomotor and vasoconstrictor outflow in human cutaneous nerves. J. Physiol. 306, 537-552.

Blair, D.A., Glover, W.E., Kidd, B.S.L., Roddie, I.C., 1960. Peripheral vascular effects of bretylium tosylate in man. Brit. J. Pharm. Chemoth. 15, 466-475.

Blumberg, H., Wallin, B.G., 1987. Direct evidence of neurally mediated vasodilatation in hairy skin of the human foot. J. Physiol. 382, 105-121.

Brengelmann, G.L., Johnson, J.M., Hermansen, L., Rowell, L.B., 1977. Altered control of skin blood-flow during exercise at high internal temperatures. J. Appl. Physiol. 43, 790794.

Brengelmann, G.L., Freund, P.R., Rowell, L.B., Olerud, J.E., Kraning, K.K., 1981. Absence of Active Cutaneous Vasodilation Associated with Congenital Absence of Sweat Glands in Humans.

Bruning, R.S., Santhanam, L., Stanhewicz, A.E., Smith, C.J., Berkowitz, D.E., Kenney, W.L., Holowatz, L.A., 2012. Endothelial nitric oxide synthase mediates cutaneous vasodilation during local heating and is attenuated in middle-aged human skin. J. Appl. Physiol. (Bethesda, Md: 1985) 112, 2019-2026.

Brunt, V.E., Minson, C.T., 2012. KCa channels and epoxyeicosatrienoic acids: major contributors to thermal hyperaemia in human skin. J. Physiol. 590, 3523-3534.

Bullard, R.W., Banerjee, M.R., Mac Intyre, B.A., 1967. The role of the skin negative feedback regulation of eccrine sweating. Int. J. Biometeorol. 11, 93-104.

Buono, M.J., Gonzalez, G., Guest, S., Hare, A., Numan, T., Tabor, B., White, A., 2010. The role of in vivo $\beta$-adrenergic stimulation on sweat production during exercise. Auton. Neurosci.: Basic and Clinical 155, 91-93.

Carter, S.J., Hodges, G.J., 2011. Sensory and sympathetic nerve contributions to the cutaneous vasodilator response from a noxious heat stimulus. Exp. Physiol. 96, 1208-1217.

Charkoudian, N., Johnson, J.M., 2000. Female reproductive hormones and thermoregulatory control of skin blood flow. Exerc. Sport Sci. Rev. 28, 108-112.

Charkoudian, N., Eisenach, J.H., Atkinson, J.L.D., Fealey, R.D., Joyner, M.J., 2002. Effects of chronic sympathectomy on locally mediated cutaneous vasodilation in humans. J. Appl. Physiol. 92, 685-690.

Cotter, J.D., Patterson, M.J., Taylor, N.A.S., 1995. The topography of eccrine sweating in humans during exercise. Eur. J. Appl. Physiol. 71, 549-554.

Crandall, C.G., Johnson, J.M., Kosiba, W.A., Kellogg, D.L., 1996. Baroreceptor control of the cutaneous active vasodilator system. J. Appl. Physiol. 81, 2192-2198.

Crandall, C.G., Shibasaki, M., Yen, T.C., 2002. Evidence that the human cutaneous venoarteriolar response is not mediated by adrenergic mechanisms. J. Physiol. 538, 599-605.

Crossley, R.J., Greenfield, A.D., Plassaras, G.C., Stephens, D., 1966. The interrelation of thermoregulatory and baroreceptor reflexes in the control of the blood vessels in the human forearm. J. Physiol. 183, 628-636.

Dolly, J.O., Aoki, K.R., 2006. The structure and mode of action of different botulinum toxins. Eur. J. Neurol. 13, 1-9.

Donadio, V., Nolano, M., Provitera, V., Stancanelli, A., Lullo, F., Liguori, R., Santoro, L., 2006. Skin sympathetic adrenergic innervation: an immunofluorescence confocal study. Ann. Neurol. 59, 376-381.

Earley, S., Heppner, T.J., Nelson, M.T., Brayden, J.E., 2005. TRPV4 forms a novel $\mathrm{Ca}^{2+}$ signal- $^{-}$ ing complex with ryanodine receptors and BKCa channels. Circ. Res. 97, 1270-1279.

Edholm, O.G., Fox, R.H., Macpherson, R.K., 1957. Vasomotor control of the cutaneous blood vessels in the human forearm. J. Physiol. 139, 455-465.

Eedy, D.J., Shaw, C., Armstrong, E.P., Johnston, C.F., Buchanan, K.D., 1990. Vasoactive intestinal peptide (VIP) and peptide histidine methionine (PHM) in human eccrine sweat glands: demonstration of innervation, specific binding sites and presence in secretions. Br. J. Dermatol. 123, 65-76.
Fagius, J., Wallin, B.G., 1980. Sympathetic reflex latencies and conduction velocities in normal man. J. Neurol. Sci. 47, 433-448.

Fagius, J., Wallin, B.G., Sundlof, G., Nerhed, C., Englesson, S., 1985. Sympathetic outflow in man after anaesthesia of the glossopharyngeal and vagus nerves. Brain 108 (Pt 2), $423-438$

Fortney, S.M., Wenger, C.B., Bove, J.R., Nadel, E.R., 1984. Effect of hyperosmolality on control of blood flow and sweating. J. Appl. Physiol. Respir. Environ. Exerc. Physiol. 57, 1688-1695.

Fox, R.H., Hilton, S.M., 1958. Bradykinin formation in human skin as a factor in heat vasodilatation. J. Physiol. 142, 219-232.

Freund, B.J., Joyner, M.J., Jilka, S.M., Kalis, J., Nittolo, J.M., Taylor, J.A., Peters, H., Feese, G., Wilmore, J.H., 1987. Thermoregulation during prolonged exercise in heat: alterations with beta-adrenergic blockade. J. Appl. Physiol. 63, 930-936.

Fujii, N., McGinn, R., Halili, L., Singh, M.S., Kondo, N., Kenny, G.P., 2015. Cutaneous vascular and sweating responses to intradermal administration of ATP: a role for nitric oxide synthase and cyclooxygenase? J. Physiol. 593, 2515-2525.

Gaskell, P., 1956. Are there sympathetic vasodilator nerves to the vessels of the hands? J. Physiol. 131, 647-656.

Gisolfi, C., Robinson, S., 1970. Central and peripheral stimuli regulating sweating during intermittent work in men. J. Appl. Physiol. 29, 761-768.

Gisolfi, C.V., Owen, M.D., Wall, P.T., Kregel, K.C., 1988. Effects of changing hypothalamic temperature on eccrine sweating in the patas monkey. Brain Res. Bull. 20, 179-182.

Go, Y.-M., Lee, H.-R., Park, H., 2012. H(2)S inhibits oscillatory shear stress-induced monocyte binding to endothelial cells Via nitric oxide production. Mol. Cell 34, 449-455.

Grant, R.T., Holling, H.E., 1938. Further observations on the vascular responses of the human limb to body warming, evidence for sympathetic vasodilator nerves in the normal subject. Clin. Sci. 3, 273-285.

Grassi, G., Seravalle, G., Turri, C., Bertinieri, G., Dell'Oro, R., Mancia, G., 2003. Impairment of thermoregulatory control of skin sympathetic nerve traffic in the elderly. Circulation 108, 729-735.

Haeusler, G., Haefely, W., Huerlimann, A., 1969. On the mechanism of the adrenergic nerve blocking action of bretylium. Naunyn Schmiedeberg's Arch. Pharmacol. 265, 260-277.

Havenith, G., Fogarty, A., Bartlett, R., Smith, C.J., Ventenat, V., 2008. Male and female upper body sweat distribution during running measured with technical absorbents. Eur. J. Appl. Physiol. 104, 245-255.

Heinzerian, P., Dey, R.D., Flux, M., Said, S.I., 1985. Deficient vasoactive intestinal peptide innervation in the sweat glands of cystic-fibrosis patients. Science 229, 1407-1408.

Heinz-Erian, P., Paul, S., Said, S.I., 1986. Receptors for vasoactive intestinal peptide on isolated human sweat glands. Peptides 7 (Suppl. 1), 151-154.

Henriksen, O., 1977. Local sympathetic reflex mechanism in regulation of blood-flow in human subcutaneous adipose-tissue. Acta Physiol. Scand. 7-48.

Hertzman, A.B., 1957. Individual differences in regional sweating. J. Appl. Physiol. 10, $242-248$

Hodges, G.J., Sparks, P.A., 2013. Contributions of endothelial nitric oxide synthase, nor adrenaline, and neuropeptide $\mathrm{Y}$ to local warming-induced cutaneous vasodilatation in men. Microvasc. Res. 90, 128-134.

Hodges, G.J., Sparks, P.A., 2014. Noradrenaline and neuropeptide Y contribute to initial, but not sustained, vasodilatation in response to local skin warming in humans. Exp. Physiol. 99, 381-392.

Hodges, G.J., Zhao, K., Kosiba, W.A., Johnson, J.M., 2006. The involvement of nitric oxide in the cutaneous vasoconstrictor response to local cooling in humans. J. Physiol. Lond. $574,849-857$.

Hodges, G.J., Kosiba, W.A., Zhao, K., Johnson, J.M., 2008. The involvement of norepinephrine, neuropeptide $\mathrm{Y}$, and nitric oxide in the cutaneous vasodilator response to local heating in humans. J. Appl. Physiol. 105, 233-240.

Hodges, G.J., Kosiba, W.A., Zhao, K., Johnson, J.M., 2009. The involvement of heating rate and vasoconstrictor nerves in the cutaneous vasodilator response to skin warming. Am. J. Physiol.-Heart C. 296, H51-H56.

Holowatz, L.A., Thompson-Torgerson, C.S., Kenney, W.L., 2008. The human cutaneous cir culation as a model of generalized microvascular function. J. Appl. Physiol. 105, 370-372.

Holzer, P., 1998. Neurogenic vasodilatation and plasma leakage in the skin. Gen. Pharmacol. 30, 5-11.

Houghton, B.L., Meendering, J.R., Wong, B.J., Minson, C.T., 2006. Nitric oxide and noradrenaline contribute to the temperature threshold of the axon reflex response to gradual local heating in human skin. J. Physiol. Lond. 572, 811-820.

Illigens, B.W., Gibbons, C., 2009. Sweat testing to evaluate autonomic function. Clin. Auton. Res. 19, 79-87.

Inoue, Y., Shibasaki, M., 1996. Regional differences in age-related decrements of the cuta neous vascular and sweating responses to passive heating. Eur. J. Appl. Physiol. 74 $78-84$.

Issekutz Jr., B., Hetenyi Jr., G., Diosy, A., 1950. Contributions to the physiology of sweat secretion. Arch. Int. Pharmacodyn. Ther. 83, 133-142.

Joannides, R., Bellien, J., Thuillez, C., 2006. Clinical methods for the evaluation of endothelial function - a focus on resistance arteries. Fundam. Clin. Pharmacol. 20, 311-320.

Johnson, J.M., 1986. Nonthermoregulatory Control of Human Skin Blood Flow.

Johnson, J.M., Kellogg Jr., D.L., 2010. Thermoregulatory and thermal control in the human cutaneous circulation. Front. Biol. 2, 825-853.

Johnson, J.M., Park, M.K., 1981. Effect of upright exercise on threshold for cutaneous vasodilation and sweating. J. Appl. Physiol. Respir. Environ. Exerc. Physiol. 50, 814-818.

Johnson, J.M., Park, M.K., 1982. Effect of heat stress on cutaneous vascular responses to the initiation of exercise. J. Appl. Physiol. Respir. Environ. Exerc. Physiol. 53, 744-749.

Johnson, J.M., Pergola, P.E., Liao, F.K., Kellogg Jr., D.L., Crandall, C.G., 1995. Skin of the dorsal aspect of human hands and fingers possesses an active vasodilator system. J. Appl. Physiol. (Bethesda, Md: 1985) 78, 948-954. 
Johnson, J.M., Minson, C.T., Kellogg, D.L., 2014. Cutaneous vasodilator and vasoconstrictor mechanisms in temperature regulation. Commun. Phys. 4, 33-89.

Journeay, W.S., Reardon, F.D., Martin, C.R., Kenny, G.P., 2004. Control of cutaneous vascu ar conductance and sweating during recovery from dynamic exercise in humans. J. Appl. Physiol. 96, 2207-2212.

Journeay, W.S., Jay, O., McInnis, N.H., LeClair, E., Kenny, G.P., 2007. Postexercise heat los and hemodynamic responses during head-down tilt are similar between genders. Med. Sci. Sports Exerc. 39, 1308-1314.

Kalsi, K.K., González-Alonso, J., 2012. Temperature-dependent release of ATP from human erythrocytes: mechanism for the control of local tissue perfusion. Exp. Physiol. 97 419-432.

Kanosue, K., Yanasefujiwara, M., Hosono, T., 1994. Hypothalamic network for thermoregulatory vasomotor control. Am. J. Phys. 267, R283-R288.

Kellogg, D.L., 2006. In Vivo Mechanisms of Cutaneous Vasodilation and Vasoconstriction in Humans During Thermoregulatory Challenges.

Kellogg Jr., D.L., Johnson, J.M., Kosiba, W.A., 1989. Selective abolition of adrenergic vasoconstrictor responses in skin by local iontophoresis of bretylium. Am. J. Phys. 257 H1599-H1606.

Kellogg Jr., D.L., Johnson, J.M., Kosiba, W.A., 1990. Baroreflex control of the cutaneous active vasodilator system in humans. Circ. Res. 66, 1420-1426.

Kellogg, D.L., Johnson, J.M., Kosiba, W.A., 1991a. Competition Between Cutaneous Active Vasoconstriction and Active Vasodilation During Exercise in Humans.

Kellogg, D.L., Johnson, J.M., Kosiba, W.A., 1991b. Control of internal temperature threshold for active cutaneous vasodilation by dynamic exercise. J. Appl. Physiol. 71, 24762482.

Kellogg Jr., D.L., Johnson, J.M., Kenney, W.L., Pergola, P.E., Kosiba, W.A., 1993. Mechanism of control of skin blood flow during prolonged exercise in humans. Am. J. Phys. 265, H562-H568.

Kellogg, D.L., Pérgola, P.E., Piest, K.L., Kosiba, W.A., Crandall, C.G., Grossmann, M., Johnson, J.M., 1995. Cutaneous active vasodilation in humans is mediated by cholinergic nerve cotransmission. Circ. Res. 77, 1222-1228.

Kellogg, D.L., Crandall, C.G., Liu, Y., Charkoudian, N., Johnson, J.M., 1998. Nitric oxide and cutaneous active vasodilation during heat stress in humans. J. Appl. Physiol. 85, 824-829.

Kellogg, D.L., Liu, Y., Kosiba, I.F., O'Donnell, D., 1999. Role of nitric oxide in the vascular ef fects of local warming of the skin in humans. J. Appl. Physiol. 86, 1185-1190.

Kellogg, D.L., Liu, Y., McAllister, K., Friel, C., Pérgola, P.E., 2002. Bradykinin does not mediate cutaneous active vasodilation during heat stress in humans. J. Appl. Physiol. 93, 1215-1221.

Kellogr Jr. D.L, Hodges, G.J., Orozco, C. R., Phillips, T.M., Zhao, J.L Johnson, J.M., 2007. Cholinergic mechanisms of cutaneous active vasodilation during heat stress in cystic fibrosis. J. Appl. Physiol. (Bethesda, Md: 1985) 103, 963-968.

Kellogg, D.L., Zhao, J.L., Wu, Y., 2008a. Endothelial nitric oxide synthase control mechanisms in the cutaneous vasculature of humans in vivo. Am. J. Physiol.-Heart C. 295 H123-H129.

Kellogg, D.L., Zhao, J.L., Wu, Y., 2008b. Neuronal nitric oxide synthase control mechanisms in the cutaneous vasculature of humans in vivo. J. Physiol. Lond. 586, 847-857.

Kellogg, D.L., Zhao, J.L., Wu, Y.B., 2009. Roles of nitric oxide synthase isoforms in cutaneous vasodilation induced by local warming of the skin and whole body heat stress in humans. J. Appl. Physiol. 107, 1438-1444.

Kellogg, D.L.,Zhao, J.L., Wu, Y.B., Johnson, J.M., 2010. VIP/PACAPreceptor mediationofcutaneous active vasodilation during heat stress in humans. J. Appl. Physiol. 109, 95-100.

Kellogg, D.L., Zhao, J.L., Wu, Y.B., Johnson, J.M., 2012. Nitric oxide and receptors for VIP and PACAP in cutaneous active vasodilation during heat stress in humans. J. Appl. Physiol. $113,1512-1518$

Kennedy, W.R., Wendelschafer-Crabb, G., Brelje, T.C., 1994. Innervation and vasculature of human sweat glands: an immunohistochemistry-laser scanning confocal fluorescence microscopy study. The Journal of Neuroscience: The Official Journal of the Society for Neuroscience. 14, 6825-6833.

Kenney, W.L., Johnson, J.M., 1992. Control of skin blood-flow during exercise. Med. Sci. Sports Exerc. 24, 303-312.

Kenney, W.L., Tankersley, C.G., Newswanger, D.L., Puhl, S.M., 1991. Alpha 1-adrenergic Blockade Does not Alter Control of Skin Blood Flow During Exercise.

Kenney, W.L., Zappe, D.H., Tankersley, C.G., Derr, J.A., 1994. Effect of systemic yohimbin on the control of skin blood-flow during local heating and dynamic exercise. Am. J. Phys. 266, H371-H376.

Kenney, W.L., Craighead, D.H., Alexander, L.M., 2014. Heat waves, aging, and human cardiovascular health. Med. Sci. Sports Exerc. 46, 1891-1899.

Kenny, G.P., Gagnon, D., Shiff, D., Armstrong, R., Journeay, W.S., Kilby, D., 2010. Influence of nonthermal baroreceptor modulation of heat loss responses during uncompensable heat stress. Eur. J. Appl. Physiol. 108, 541-548.

Kondo, N., Horikawa, N., Aoki, K., Shibasaki, M., Inoue, Y., Nishiyasu, T., Crandall, C.G., 2002. Sweating responses to a sustained static exercise is dependent on thermal load in humans. Acta Physiol. Scand. 175, 289-295.

Koroxeni. G, Marshall RJ and Shepherd JT. Cardiovascular response to acute heat stress. J. Appl. Physiol.. 1961;16:869-\&.

Kummer, W., Herbst, W.M., Heym, C., 1990. Vasoactive intestinal polypeptide receptor like immunoreactivity in human sweat glands. Neurosci. Lett. 110, 239-243.

Kuno, Y., 1956. Human Perspiration. CC Thomas, Springfield, Illinois.

Kutz, J.L., Greaney, J.L., Santhanam, L., Alexander, L.M., 2015. Evidence for a functional vasodilatatory role for hydrogen sulphide in the human cutaneous microvasculature. J. Physiol. Lond. 593, 2121-2129.

Lee, K., Mack, G.W., 2006. Role of nitric oxide in methacholine-induced sweating and vasodilation in human skin. J. Appl. Physiol. 100, 1355-1360.

Lewis, T., Pickering, G., 1931. Vasodilation in the limbs in response to warming the body; with evidence for sympathetic vasodilator nerves in man. Heart 16, 33-51.
Li, L., Liu, D., Bu, D., Chen, S., Wu, J., Tang, C., Du, J., Jin, H., 1833. Brg1-dependent epigenetic control of vascular smooth muscle cell proliferation by hydrogen sulfide. Biochimica et Biophysica Acta (BBA) - Molecular Cell Research. 2013, 1347-1355.

Lind, A.R., Leithead, C.S., McNicol, G.W., 1968. Cardiovascular changes during syncope induced by tilting men in the heat. J. Appl. Physiol. 25, 268-276.

Lindh, B., Hokfelt, T., 1990. Structural and functional aspects of acetylcholine peptide coexistence in the autonomic nervous system. Prog. Brain Res. 84, 175-191.

Lindsay, S.L., Elder, H.Y., Tavadia, S., Bovell, D.L., 2002a. Immunolocalisation of the P2Y(1), $\mathrm{P} 2 \mathrm{Y}(2)$ and $\mathrm{P} 2 \mathrm{Y}(4)$ receptor subtypes in human eccrine sweat glands. J. Physiol. Lond. $543,92 \mathrm{p}-93 \mathrm{p}$

Lindsay, S.L., Holdsworth, R., Tavadia, S., Bovell, D.L., 2002b. Immunolocalisation of P2Y(2) receptor subtype in human hyperhidrotic eccrine sweat glands. Brit. J. Pharmacol. 137.

Lloyd, D.P., 1961. Temperature and the action of sweat glands. Proc. Natl. Acad. Sci. U. S. A. $47,358-362$.

Longmore, J., Jani, B., Bradshaw, C.M., Szabadi, E., 1986. Effects of locally administered anticholinesterase agents on the secretory response of human eccrine sweat glands to acetylcholine and carbachol. Br. J. Clin. Pharmacol. 21, 131-135.

Low, V.A., Sandroni, P., Fealey, R.D., Low, P.A., 2006. Detection of small-fiber neuropathy by sudomotor testing. Muscle Nerve 34, 57-61.

Lundberg, J.M., 1996. Pharmacology of cotransmission in the autonomic nervous system: integrative aspects on amines, neuropeptides, adenosine triphosphate, amino acids and nitric oxide. Pharmacol. Rev, 48, 113-178.

Lundberg, J.M., Änggärd, A., Fahrenkrug, J., Hökfelt, T., Mutt, V., 1980. Vasoactive intestinal polypeptide in cholinergic neurons of exocrine glands: functional significance of coexisting transmitters for vasodilation and secretion. Proc. Natl. Acad. Sci. U. S. A. $77,1651-1655$

Lundberg, J., Norgren, L., Ribbe, E., Rosen, I., Steen, S., Thorne, J., Wallin, B.G., 1989. Direct evidence of active sympathetic vasodilatation in the skin of the human foot. J. Physiol. Lond. 417, 437-446.

Machado-Moreira, C., Smith, F., van den Heuvel, A.J., Mekjavic, I., Taylor, N.S., 2008a. Sweat secretion from the torso during passively-induced and exercise-related hyperthermia. Eur. J. Appl. Physiol. 104, 265-270.

Machado-Moreira, C., Wilmink, F., Meijer, A., Mekjavic, I., Taylor, N.S., 2008b. Local differences in sweat secretion from the head during rest and exercise in the heat. Eur. J. Appl. Physiol. 104, 257-264.

Machado-Moreira, C.A., Caldwell, J.N., Mekjavic, I.B., Taylor, N.A.S., 2008c. Sweat secretion from palmar and dorsal surfaces of the hands during passive and active heating. Aviat. Space Environ. Med. 79, 1034-1040.

Machado-Moreira, C.A., McLennan, P.L., Lillioja, S., van Dijk, W., Caldwell, J.N., Taylor, N.A.S., 2012. The cholinergic blockade of both thermally and non-thermally induced human eccrine sweating. Exp. Physiol. 97, 930-942.

MacIntyre, B.A., Bullard, R.W., Banerjee, M., Elizondo, R., 1968. Mechanism of Enhancement of Eccrine Sweating by Localized Heating.

Mack, G.W., Shannon, L.M., Nadel, E.R., 1986. Influence of beta-adrenergic blockade on the control of sweating in humans. J. Appl. Physiol. 61, 1701-1705.

Magerl, W., Treede, R.D., 1996. Heat-evoked vasodilatation in human hairy skin: axon reflexes due to low-level activity of nociceptive afferents. J. Physiol. Lond. 497, 837-848.

McCord, G.R., Cracowski, J.L., Minson, C.T., 2006. Prostanoids contribute to cutaneous active vasodilation in humans. Am J Physiol-Reg I. 291, R596-R602.

McInnis, N.H., Journeay, W.S., Jay, O., Leclair, E., Kenny, G.P., 2006. 15 degrees head-down tilt attenuates the postexercise reduction in cutaneous vascular conductance and sweating and decreases esophageal temperature recovery time. J. Appl. Physiol. $101,840-847$

McNamara, T.C., Keen, J.T., Simmons, G.H., Alexander, L.M., Wong, B.J., 2014. Endothelial nitric oxide synthase mediates the nitric oxide component of reflex cutaneous vasodilatation during dynamic exercise in humans. J. Physiol. Lond. 592, 5317-5326.

Milner, R., Bodin, R., Guiducci, S., Del Rosso, A., Kahaleh, M.B., Matucci-Cerinic, M., Burnstock, G., 2004. Regulation of substance P mRNA expression in human dermal microvascular endothelial cells. Clin. Exp. Rheumatol. 22, S24-S27.

Minson, C.T., Wladkowski, S.L., Cardell, A.F., Pawelczyk, J.A., Kenney, W.L., 1998. Age alters the cardiovascular response to direct passive heating. J. Appl. Physiol. 84, 1323-1332.

Minson, C.T., Berry, L.T., Joyner, M.J., 2001. Nitric oxide and neurally mediated regulation of skin blood flow during local heating. J. Appl. Physiol. 91, 1619-1626.

Montain, S.J., Latzka, W.A., Sawka, M.N., 1995. Control of thermoregulatory sweating is altered by hydration level and exercise intensity. J. of Appl. Physiol. (Bethesda, Md: 1985) $79, \quad 1434-1439$

Moorhouse, V.H.K., 1911. Effect of increased temperature of the carotid blood. Am. J. Phys. $28,223-234$

Mora-Rodriguez, R., Gonzalez-Alonso, J., Below, P.R., Coyle, E.F., 1996. Plasma catecholamines and hyperglycaemia influence thermoregulation in man during prolonged exercise in the heat. J. Physiol. 491 (Pt 2), 529-540.

Nadel, E.R., Bullard, R.W., Stolwijk, J.A., 1971. Importance of skin temperature in the regulation of sweating. J. Appl. Physiol. 31, 80-87.

Namer, B., Bickel, A., Kramer, H., Birklein, F., Schmelz, M., 2004. Chemically and electrically induced sweating and flare reaction. Auton. Neurosci.-Basic. 114, 72-82.

Ogawa T. Local effect of skin temperature on threshold concentration of sudorific agents J. Appl. Physiol.. 1970;28:18-\&.

Ogawa, T., Asayama, M., 1986. Quantitative-analysis of the local effect of skin temperature on sweating. Jpn. J. Physiol. 36, 417-422.

Ogawa, T., Bullard, R.W., 1972. Characteristics of subthreshold sudomotor neural impulses. J. Appl. Physiol. 33, 300-305.

Ogawa, T., Sugenoya, J., 1993. Pulsatile sweating and sympathetic sudomotor activity. Jpn. J. Physiol. 43, 275-289.

Ott, I., 1887. The heat-center in the brain. J. Nerv, Ment. Dis. 14, 152-162. 
Pearson, J., Low, D.A., Stöhr, E., Kalsi, K., Ali, L., Barker, H., González-Alonso, J., 2011. Hemodynamic responses to heat stress in the resting and exercising human leg: insight into the effect of temperature on skeletal muscle blood flow. Am. J. Physiol. Regul. Integr. Comp. Physiol. 300, R663-R673.

Pescatello, L.S., Mack, G.W., Leach, C.N., Nadel, E.R., 1987. Effect of beta-adrenergic blockade on thermoregulation during exercise. J. Appl. Physiol. 62, 1448-1452.

Pescatello, L.S., Mack, G.W., Leach, C.N., Nadel, E.R., 1990. Thermoregulation in mildly hy pertensive men during beta-adrenergic-blockade. Med. Sci. Sports Exerc. 22, 222228

Rabasseda, X., Solsona, C., Marsal, J., Egea, G., Bizzini, B., 1987. ATP release from pure cholinergic synaptosomes is not blocked by tetanus toxin. FEBS Lett. 213, 337-340.

Roddie, I., 1983. Circulation to skin and adipose tissue. In: Shepherd, J., Abboud, F. (Eds.), Handbook of Physiology: The Cardiovascular System. Am. Physiol. Soc, Bethesda, MD

Roddie, I.C., Shepherd, J.T., Whelan, R.F., 1957. The contribution of constrictor and dilator nerves to the skin vasodilation during body heating. J. Physiol. Lond. 136, 489-497.

Rowell, L.B., 1974. Human cardiovascular adjustments to exercise and thermal-stress. Physiol. Rev. 54, 75-159.

Rowell, L.B., Wyss, C.R., Gl, B., 1973. Sustained human skin and muscle vasoconstriction with reduced baroreceptor activity. J. Appl. Physiol. 34, 639-643.

Saad, A.R., Stephens, D.P., Bennett, L.A.T., Charkoudian, N., Kosiba, W.A., Johnson, J.M., 2001. Influence of isometric exercise on blood flow and sweating in glabrous and nonglabrous human skin. J. Appl. Physiol. 91, 2487-2492.

Saito, M., Naito, M., Mano, T., 1990. Different responses in skin and muscle sympatheticnerve activity to static muscle-contraction. J. Appl. Physiol. 69, 2085-2090.

K Sato. On the mechanism of sweat secretion from the foot of the cat J Orient Med. 11:99, 1929 (Japanese) cited by Kuno, Y. IN: Human Perspiration 1956: CC Thomas; Springfield, Illinois

Sato, K., Sato, F., 1981. Pharmacologic Responsiveness of Isolated Single Eccrine Sweat Glands.

Saumet, J.L., Kellogg, D.L., Taylor, W.F., Johnson, J.M., 1988. Cutaneous laser-Doppler flowmetry - influence of underlying muscle blood-flow. J. Appl. Physiol. 65, 478481.

Savage, M.V., Brengelmann, G.L., 1996. Control of skin blood flow in the neutral zone of human body temperature regulation. J. Appl. Physiol. 80, 1249-1257.

Savage, M.V., Brengelmann, G.L., Buchan, A.M.J., Freund, P.R., 1990. Cystic-fibrosis, vasoac tive intestinal polypeptide, and active cutaneous vasodilation. J. Appl. Physiol. 69, 2149-2154.

Sawka, M.N., Young, A.J., Francesconi, R.P., Muza, S.R., Pandolf, K.B., 1985. Thermoregula tory and Blood Responses During Exercise at Graded Hypohydration Levels.

Schlader, Z.J., Gagnon, D., Lucas, R.A.I., Pearson, J., Crandall, C.G., 2015. Baroreceptor Unloading Does not Limit Forearm Sweat Rate During Severe Passive Heat Stress.

Schlereth, T., Dittmar, J.O., Seewald, B., Birklein, F., 2006. Peripheral amplification of sweating - a role for calcitonin gene-related peptide. J. Physiol. 576, 823-832.

Shastry, S., Dietz, N.M., Halliwill, J.R., Reed, A.S., Joyner, M.J., 1998. Effects of nitric oxide synthase inhibition on cutaneous vasodilation during body heating in humans. J. Appl. Physiol. 85, 830-834.

Shastry, S., Minson, C.T., Wilson, S.A., Dietz, N.M., Joyner, M.J., 2000. Effects of atropine and L-NAME on cutaneous blood flow during body heating in humans. J. Appl. Physiol. 88, 467-472.

Shibasaki, M., Crandall, C.G., 2001. Effect of Local Acetylcholinesterase Inhibition on Sweat Rate in Humans.

Shibasaki, M., Davis, S.L., Cui, J., Low, D.A., Keller, D.M., Durand, S., Crandall, C.G., 2006 Neurally mediated vasoconstriction is capable of decreasing skin blood flow during orthostasis in the heat-stressed human. J. Physiol. Lond. 575, 953-959.

Shimizu, Y., Sakai, M., Umemura, Y., Ueda, H., 1997. Immunohistochemical localization of nitric oxide synthase in normal human skin: expression of endothelial-type and in ducible-type nitric oxide synthase in keratinocytes. J. Dermatol. 24, 80-87.

Simpson, L.L., 1981. The origin, structure, and pharmacological activity of botulinum toxin. Pharmacol. Rev. 33, 155-188.

Smith, C., Havenith, G., 2011. Body mapping of sweating patterns in male athletes in mild exercise-induced hyperthermia. Eur. J. Appl. Physiol. 111, 1391-1404.

Smith, C.J., Havenith, G., 2012. Body mapping of sweating patterns in athletes: a sex comparison. Med. Sci. Sports Exerc. 44, 2350-2361.

Smith, C.J., Santhanam, L., Bruning, R.S., Stanhewicz, A., Berkowitz, D.E., Holowatz, L.A., 2011. Upregulation of inducible nitric oxide synthase contributes to attenuated cutaneous vasodilation in essential hypertensive humans. Hypertension 58, 935-942.

Smith, C.J., Alexander, L.M., Kenney, W.L., 2013a. Nonuniform, age-related decrements in regional sweating and skin blood flow. Am. J. Physiol. Regul. Integr. Comp. Physiol, 305, R877-R885.

Smith, C.J., Kenney, W.L., Alexander, L.M., 2013b. Regional relation between skin blood flow and sweating to passive heating and local administration of acetylcholine in young, healthy humans. Am. J. Physiol. Regul. Integr. Comp. Physiol_304, R566-R573.

Stapleton, J.M., Fujii, N., Carter, M., Kenny, G.P., 2014. Diminished nitric oxide-dependent sweating in older males during intermittent exercise in the heat. Exp. Physiol. 99, 921-932.

Stephens, D.P., Charkoudian, N., Benevento, J.M., Johnson, J.M., Saumet, J.L., 2001. The in fluence of topical capsaicin on the local thermal control of skin blood flow in humans. Am. J. Physiol.-Reg. I. 281, R894-R901.

Sugenoya, J., Iwase, S., Mano, T., Sugiyama, Y., Ogawa, T., Nishiyama, T., Nishimura, N., Kimura, T., 1998. Vasodilator component in sympathetic nerve activity destined for the skin of the dorsal foot of mildly heated humans. J. Physiol. 507, 603-610.

Tainio, H., Vaalasti, A., Rechardt, L., 1987. The distribution of substance P-, CGRP-, galanin and ANP-like immunoreactive nerves in human sweat glands. Histochem. J. 19, 375-380.

Taylor, W.F., Johnson, J.M., Oleary, D., Park, M.K., 1984. Effect of high local temperature on reflex cutaneous vasodilation. J. Appl. Physiol. 57, 191-196.
Taylor, W.F., Johnson, J.M., Kosiba, W.A., Kwan, C.M., 1988. Graded cutaneous vascular-responses to dynamic leg exercise. J. Appl. Physiol. 64, 1803-1809.

Taylor, W.F., Johnson, J.M., Kosiba, W.A., Kwan, C.M., 1989. Cutaneous vascular-response to isometric handgrip exercise. J. Appl. Physiol. 66, 1586-1592.

Taylor, N.A.S., Caldwell, F.N., Mekjavic, I.B., 2006. The sweating foot: local differences in sweat secretion during exercise-induced hyperthermia. Aviat. Space Envir. Md. 77, 1020-1027.

Tew, G.A., Klonizakis, M., Moss, J., Ruddock, A.D., Saxton, J.M., Hodges, G.J., 2011a. Role of sensory nerves in the rapid cutaneous vasodilator response to local heating in young and older endurance-trained and untrained men. Exp. Physiol. 96, 163-170.

Tew, G.A., Saxton, J.M., Klonizakis, M., Moss, J., Ruddock, A.D., Hodges, G.J., 2011b. Aging and aerobic fitness affect the contribution of noradrenergic sympathetic nerves to the rapid cutaneous vasodilator response to local heating. J. Appl. Physiol. 110, 1264-1270.

Uno, H., 1977. Sympathetic innervation of sweat glands and piloarrector muscles of ma caques and human beings. J. Investig. Dermatol. 69, 112-120.

Vaalasti, A., Tainio, H., Rechardt, L., 1985. Vasoactive intestinal polypeptide (VIP)-like immunoreactivity in the nerves of human axillary sweat glands. J. Investig. Dermatol. 85, 246-248.

van Beaumont, W., Bullard, R.W., 1966. Sweating exercise stimulation during circulatory arrest. Science 152, 1521-1523.

Vanbeaumont W and Bullard RW. Sweating - its rapid response to muscular work. Science. $1963 ; 141: 643-\&$.

Vissing, S.F., Hjortso, E.M., 1996. Central motor command activates sympathetic outflow to the cutaneous circulation in humans. J. Physiol. Lond. 492, 931-939.

Vissing, S.F., Scherrer, U., Victor, R.G., 1994. Increase of sympathetic discharge to skeletal muscle but not to skin during mild lower body negative pressure in humans. J. Physiol. 481, 233-241.

Vissing, S.F., Secher, N.H., Victor, R.G., 1997. Mechanisms of cutaneous vasoconstriction during upright posture. Acta Physiol. Scand. 159, 131-138.

Wallin, B.G., 1990. Neural control of human skin blood-flow. J. Auton. Nerv. Syst. 30, S185-S190.

Wallin, B.G., Sundlof, G., Delius, W., 1975. The effect of carotid sinus nerve stimulation on muscle and skin nerve sympathetic activity in man. Pflugers Arch. - Eur. J. Physiol. $358,101-110$.

Welch, G., Foote, K.M., Hansen, C., Mack, G.W., 2009a. Nonselective NOS inhibition blunts the sweat response to exercise in a warm environment. J. Appl. Physiol. 106, 796803

Welch, G., Foote, K.M., Hansen, C., GW, M., 2009b. Nonselective NOS inhibition blunts the sweat response to exercise in a warm environment. J. Appl. Physiol. (Bethesda, Md: 1985) 106, 796-803.

Wilcox, R.G., Bennett, T., Macdonald, I.A., Herbert, M., Skene, A.M., 1984. The effects of acute or chronic ingestion of propranolol or metoprolol on the physiological re sponses to prolonged, submaximal exercise in hypertensive men. Br. J. Clin. Pharmacol. 17, 273-281.

Wilkins, B.W., Chung, L.H., Tublitz, N.J., Wong, B.J., Minson, C.T., 2004. Mechanisms of vasoactive intestinal peptide-mediated vasodilation in human skin. J. Appl. Physiol. (Bethesda, Md: 1985) 97, 1291-1298.

Wilson, T.E., Cui, J., Crandall, C.G., 2001. Absence of arterial baroreflex modulation of skin sympathetic activity and sweat rate during whole-body heating in humans. J. Physiol $536,615-623$.

Wolf, J.E., Maibach, H.I., 1974. Palmar eccrine sweating - the role of adrenergic and cholinergic mediators. Br. J. Dermatol. 91, 439-446.

Wong, B.J., 2013. Sensory nerves and nitric oxide contribute to reflex cutaneous vasodilation in humans. Am. J. Physiol.-Reg. I. 304, R651-R656.

Wong, B.J., Fieger, S.M., 2012. Transient receptor potential vanilloid type 1 channels con tribute to reflex cutaneous vasodilation in humans. J. Appl. Physiol. (Bethesda, Md: 1985) $112,2037-2042$

Wong, B.J., Minson, C.T., 2006. Neurokinin-1 receptor desensitization attenuates cutaneous active vasodilatation in humans. J. Physiol. 577, 1043-1051.

Wong, B.J., Wilkins, B.W., Minson, C.T., 2004. H1 but not H2 histamine receptor activation contributes to the rise in skin blood flow during whole body heating in humans. J. Physiol. 560, 941-948.

Wurster, R.D., McCook, R.D., 1969. Influence of rate of change in skin temperature on sweating. J. Appl. Physiol. 27, 237-240.

Yamashita, Y., Ogawa, T., Ohnishi, N., Imamura, R., Sugenoya, J., 1987. Local effect of vasoactive intestinal polypeptide on human sweat-gland function. Jpn J Physiol. 37, 929-936.

Yamazaki, F., Sone, R., Ikegami, H., 1994. Responses of Sweating and Body Temperature to Sinusoidal Exercise.

Yamazaki, F., Fujii, N., Sone, R., Ikegami, H., 1996. Responses of Sweating and Body Tem perature to Sinusoidal Exercise in Physically Trained men.

Yanagimoto, S., Kuwahara, T., Zhang, Y., Koga, S., Inoue, Y., Kondo, N., 2003. Intensitydependent thermoregulatory responses at the onset of dynamic exercise in mildly heated humans. Am. J. Physiol.-Reg. I. 285, R200-R207.

Yu, X.-H., Cui, L.-B., Wu, K., Zheng, X.-L., Cayabyab, F.S., Chen, Z.-W., Tang, C.-K., 2014. Hydrogen sulfide as a potent cardiovascular protective agent. Clin. Chim. Acta 437, $78-87$

Zelis, R., Mason, D.T., Braunwald, E., 1969. Partition of blood flow to the cutaneous and muscular beds of the forearm at rest and during leg exercise in normal subjects and in patients with heart failure. Circ. Res. 24, 799-806.

Zhong, L., Lv, L., Yang, J., Liao, X., Yu, J., Wang, R., Zhou, P., 2014. Inhibitory effect of hydrogen sulfide on platelet aggregation and the underlying mechanisms. J. Cardiovasc. Pharmacol. 64, 481-487. 